Research Article

\title{
Geomechanical Model Experiment Study on Deformation and Failure Mechanism of the Mountain Tunnel in Layered Jointed Rock Mass
}

\author{
Zhibiao Guo $\mathbb{D}^{1,2}$ Jinyan Fan $\mathbb{D}^{1},{ }^{1,2}$ Fengnian Wang $\mathbb{D},{ }^{1,2}$ Hongbo Zhou, ${ }^{3}$ and Wei Li ${ }^{1,2}$ \\ ${ }^{1}$ School of Mechanics and Civil Engineering, China University of Mining and Technology (Beijing), Beijing 100083, China \\ ${ }^{2}$ State Key Laboratory for Geo-Mechanics and Deep Underground Engineering, \\ China University of Mining and Technology (Beijing), Beijing 100083, China \\ ${ }^{3}$ Nonferrous Geological Exploration and Research Institute Limited Liability Company, Shenyang 110013, China
}

Correspondence should be addressed to Jinyan Fan; bqt1700602043@student.cumtb.edu.cn

Received 24 October 2020; Revised 20 November 2020; Accepted 30 January 2021; Published 13 February 2021

Academic Editor: Hugo Rodrigues

Copyright (C) 2021 Zhibiao Guo et al. This is an open access article distributed under the Creative Commons Attribution License, which permits unrestricted use, distribution, and reproduction in any medium, provided the original work is properly cited.

\begin{abstract}
The Minxian tunnel is a key engineering of the Weiyuan-Wudu expressway that is excavated in layered jointed carbonaceous slate rock mass. During the construction process, the surrounding rocks of the tunnel encountered serious large deformations and failure, which brought about great difficulties to the safety and cost of the tunnel. In order to study the deformation and failure mechanism of the surrounding rocks, a physical model test was conducted, and integrated methods including strain gauges, a digital camera, and noncontact full-field digital imaging correlation technique were used to record the response information of the surrounding rocks. The evolution process of surrounding rocks failure was simulated successfully in the model test, and the deformation characteristics were basically consistent with the actual engineering. The modelling results show that concentrated stresses in the surrounding rocks were very uneven due to developed stratified and jointed rock mass structure. The maximum and minimum concentrated stresses appeared at the vault of the tunnel and left of inverted arc area, and concentration factors were 3.11 and 1.98, respectively. The main forms of surrounding rocks deformation and failure were large area spalling of surface, severe circumferential fractures, serious bending deformations of thin rock layers, and collapse of overlying strata. The maximum displacements occurred at left sidewall and right shoulder of the tunnel and the corresponding actual displacements were $460 \mathrm{~mm}$ to $500 \mathrm{~mm}$. Caving and failure took place firstly at several key positions with maximum concentrated stresses or displacements and subsequently gave rise to massive collapse of surrounding rocks.
\end{abstract}

\section{Introduction}

With the development of western China, varieties of rock engineering including traffic facilities such as railway, metro, expressway connecting the western region and other developed areas, mining projects, slopes, and hydropower stations have increased rapidly in recent years. At the same time, more difficult and complicated geotechnical problems occur during the construction process [1-8]. Due to the mountainous landforms and complicated conditions, some tunnel engineering with different geological characteristics appeared in this area such as the Wushaoling tunnel with a maximum buried depth of $1100 \mathrm{~m}$ and a total length of
$20.05 \mathrm{~km}$ [9], the Humaling tunnel excavated in tertiary poorly cemented and water-rich sandstone [10], and the Zhegushan tunnel passing through extremely soft phyllite [11]. Phenomena of serious surrounding rock deformations and the supports failure occurred during the construction, which not only threatened the safety of workers but also brought about numerous economic losses. The stability of the tunnel is influenced by many aspects including geological factors such as rock lithology, joints, fissures, beddings, foliations or faults, stress factors such as in situ stresses, excavation unloading and stress redistribution, and other factors such as tunnelling method and construction procedure, which results in the fact that different tunnels 
always have complicated deformation characteristics and failure mechanism. Therefore, no matter the support design of new tunnels or the repair and reinforcement of failed tunnels, it is the most important premise for ensuring the stabilization of the tunnel to understand deformation and failure mechanism of the tunnel as fully and accurately as possible.

Physical modelling test is one of effective research methods to study the deformation process and failure mechanism in rock mechanics and rock engineering [12-15]. The carefully designed model tests based on the similarity theory firstly can simulate not only the engineering structure and surrounding rocks but also the discontinuous planes such as bedding and fault [16]; secondly they can be able to record the whole process of deformation and failure of geotechnical engineering structures under a specific stress state and can reflect the mechanical characteristics of geotechnical engineering quantitatively or qualitatively [17]; thirdly they are more intuitive and easier to understand the failure mechanism of the underground openings, the variation trend, and stability conditions $[18,19]$. A plenty of works have been carried out to study the stability and deformation mechanism of tunnels excavated in layered jointed rock mass through physical model tests. For example, Park et al. [20] developed the trap door model tests to study the mechanical behavior of surrounding rocks excavated in inclined layered jointed rock mass and found that the stress arching around the opening had an important effect on the distribution law of vertical stress and ground surface settlement. Jeon et al. [21] performed scaled model tests to investigate the effects of a fault and grouting on the stability of a tunnel. The experimental results showed that the displacements at sidewalls of the tunnel were relatively larger than other positions due to the shear failure along the weak planes. He et al. [22-24] developed a new modelling method called physically finite elementary slab assemblage (PFESA), and a series of geomechanical model tests were carried out to systematically study deformation characteristics and mechanical responses of surrounding rocks around the underground roadways excavated in the stratified rock masses with dip angles of $0^{\circ}, 45^{\circ}$, and $90^{\circ}$, respectively. The results showed that shear failure of bedding planes caused by the effect of excavation disturbance was the dominant failure mechanism of surrounding rocks. Lei et al. [25] studied systematically the distribution and change laws of lining and surrounding rocks stress and failure mechanism of the shallow buried tunnel with different bias angle of ground surface under unsymmetrical loading through physical model tests. They found that the tunnel failure started from local displacement and developed to surface tensile fracture in higher stress area and to shear failure of deep surrounding rocks finally. Sun et al. [26] carried out a physical modelling test to examine the deformation mechanism of the tunnel excavated in deep stratified jointed soft rock mass. They considered that bedding planes had an inevitable influence on the deformation and failure of surrounding rocks during the excavation processes. However, these studies are still insufficient and there is room for further research. We have the following examples: (a) One of the most important characteristics of the layered jointed surrounding rocks is that bedding planes have significant influences on stability of the tunnel. However, the stratification effects are not obvious in most of model tests that adopted the method of cast-in-place analogous material to construct the physical model and used mica powder as the layering material between two simulated strata. (b) Benching tunnelling method is the most commonly used in construction of large-span tunnel. But bench-forming process of tunnel face is always replaced by full-section excavation in laboratory modelling tests due to the limits of simulated tunnel cross section. It may be sure that the mechanical responses of surrounding rocks are different when using two excavation methods.

In this study, a geomechanical model test was carried out using the modelling method, PFESA, to study the deformation process, characteristics, and failure mechanism of the Minxian tunnel excavated in layered jointed rock mass with a fault during different construction steps and provide a comprehensive and reasonable basis for the safety supporting of the tunnel. Firstly, engineering geological conditions of the Minxian tunnel were introduced and reviewed. Secondly, similarity ratios were established based on the actual engineering and similarity theory. The test scheme including excavation procedure, stress loading path, and monitoring plan of surrounding rocks responses was carefully designed. Finally, the deformation process and failure mechanism of surrounding rocks were investigated and analyzed.

\section{Engineering Background}

2.1. Geological Conditions. The Minxian tunnel is located in Min county of Dingxi city in Gansu province, China (Figure 1(a)), and it is a dominant engineering of the Weiyuan-Wudu section of Lanzhou-Haikou expressway (G75). The tunnel is a twin-mountain tunnel with the length of $2800 \mathrm{~m}$, and the minimum distance between left and right tunnels is $28 \mathrm{~m}$ appearing at the entrance and exit (Figure 1(b)). The maximum buried depth of the tunnel is $287 \mathrm{~m}$ (Figure 1(c)). The shape of cross section is horseshoe, and its area is about $110 \mathrm{~m}^{2}$. The three-bench tunnelling method with $4.8 \mathrm{~m}$ in length along longitudinal direction was adopted as the layout of the tunnel face. The surrounding rocks of the tunnel are mainly black, mud-altered residual texture and strongly or medium weathered carbonaceous slate and scattered intercalated siltstone (Figure 1(c)). Due to intense folding and complex tectonic motions in this area, the surrounding rocks are strongly or medium weathered and the foliations and joints of carbonaceous slate are very developed. According to the Standard for Engineering Classification of Rock Mass, the surrounding rocks of the tunnel are classified in grades $\mathrm{V}$, the worst rock mass quality.

There are two large reverse faults (F2 and F24) filled with breccia, fault gouge, and crushed rock along the tunnelling direction (Figure $1(\mathrm{c})$ ). The occurrence of F2 is $\mathrm{NE} 47^{\circ} \angle 60^{\circ}$, and the width of fracture zone is about $360 \mathrm{~m}$; F24 is 


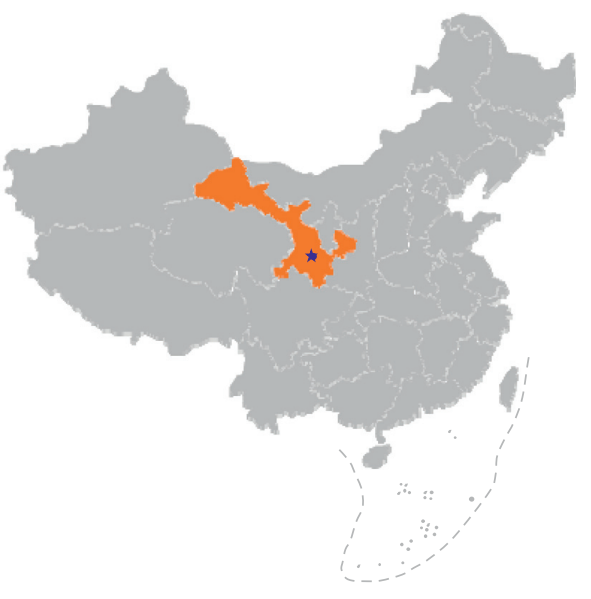

(a)

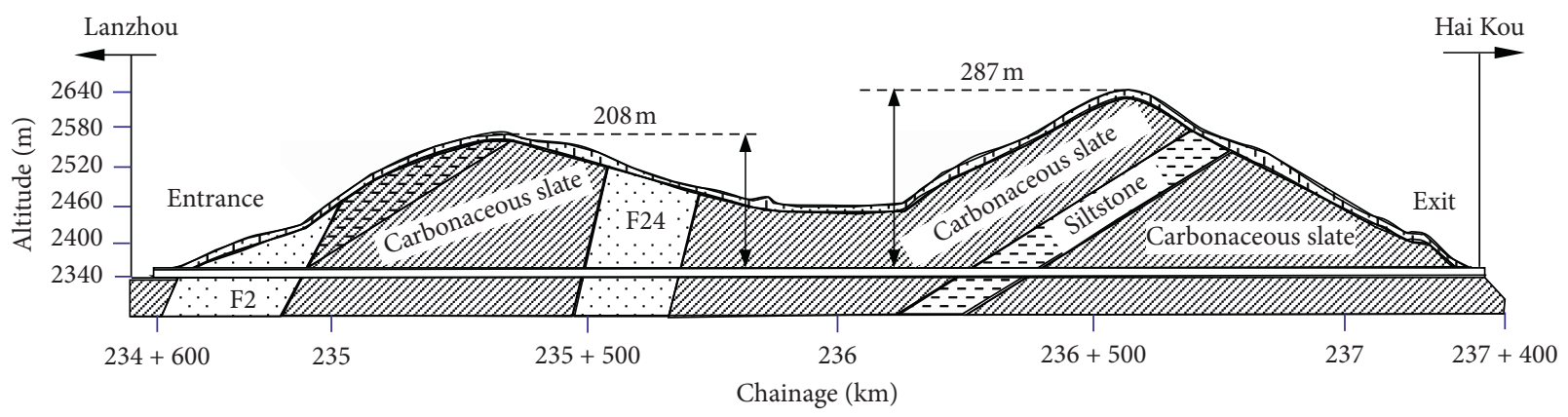

(c)

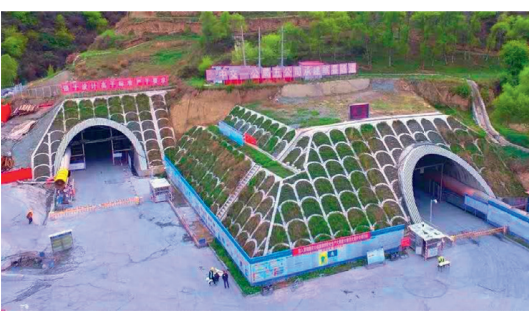

Min County, Gansu, China (b)

FIgUre 1: Profile of the Minxian tunnel.

NE $43^{\circ} \angle 76^{\circ}$ and about $200 \mathrm{~m}$. There were still some small faults during the excavation, which caused the angular unconformity of layered slate and led to asymmetric deformation of the tunnel. The hydraulic fracturing method was adopted by the project department to measure the in situ stress. The minimum horizontal principal stress $\sigma_{3}$ was $3.45 \mathrm{MPa}$ and the orientation was $N 78^{\circ} \mathrm{W}$. The maximum horizontal principal stress $\sigma_{1}$ was $5.56 \mathrm{MPa}$ and the orientation was $\mathrm{N} 7^{\circ} \mathrm{E}$. The angle between $\sigma_{1}$ and the axial direction of tunnel was $5-13^{\circ}$. At the measurement position, the thickness of the mountain is about $180 \mathrm{~m}$, and the density of slate is $2460 \mathrm{~kg} / \mathrm{cm}^{3}$. The middle principal stress $\sigma_{2}$ was $4.27 \mathrm{MPa}$, which was approximately equal to the gravity caused by overlying rock mass of the tunnel. The lateral stress coefficient defined as $\sigma_{1} / \sigma_{2}$ is 1.30 , and the ratio of $\sigma_{3} / \sigma_{1}$ is 0.62 .

2.2. Failure Phenomena. Composite supporting technologies were used for the safety of the tunnel. The primary supports included heavy HW175 steel frames $(40.3 \mathrm{~kg} / \mathrm{m})$ at $0.6 \mathrm{~m}$ spacing along the longitudinal axis, steel mesh with the diameter of $8 \mathrm{~mm}$ steel, $26 \mathrm{~cm}$ thickness of C25 sprayed concrete, and ordinary rock bolts with diameter of $25 \mathrm{~mm}$, length of $3.5 \mathrm{~m}$, and interval of $1.0 \mathrm{~m} \times 1.0 \mathrm{~m}$. The secondary support was reinforced concrete lining with a thickness of $600 \mathrm{~mm}$.

When the buried depth was small, the supporting measures could control deformations of surrounding rocks. However, with the increase of the buried depth, the deformations increased greatly and continuously. For example, when the heading face of right tunnel approached the drainage divide (mileage: $235+478 \sim 235+482 \mathrm{~km}$ ), the maximum deformation of surrounding rock appeared at waist and the cumulative value reached $300 \mathrm{~mm}$ during seven days. With the deformation increasing, the sprayed concrete began to crack and steel frames deformed gradually. Two months later, the maximum crown settlement and deformation of sidewall reached $400 \mathrm{~mm}$ and $1200 \mathrm{~mm}$, respectively (Figure 2). Then, the failed primary supports had to be removed and replaced.

\section{Model Test}

3.1. Testing Machine. The biaxial loading geomechanical simulation apparatus (Figure 3), developed by State Key Laboratory for Geo-Mechanics and Deep Underground Engineering, consists of the frame system, the loading system, the pressure stabilizing system, and the control console. The sizes of testing machine (length $\times$ height $\times$ width) are $1600 \mathrm{~mm} \times 1600 \mathrm{~mm} \times 400 \mathrm{~mm}$. The machine can be loaded from top, left, and right directions independently through eighteen hydraulic plates, and the maximum load of each plate is $5 \mathrm{MPa}$. The load stabilization is achieved through an intelligent hydraulic system, and the maintenance time can reach 300 hours. 


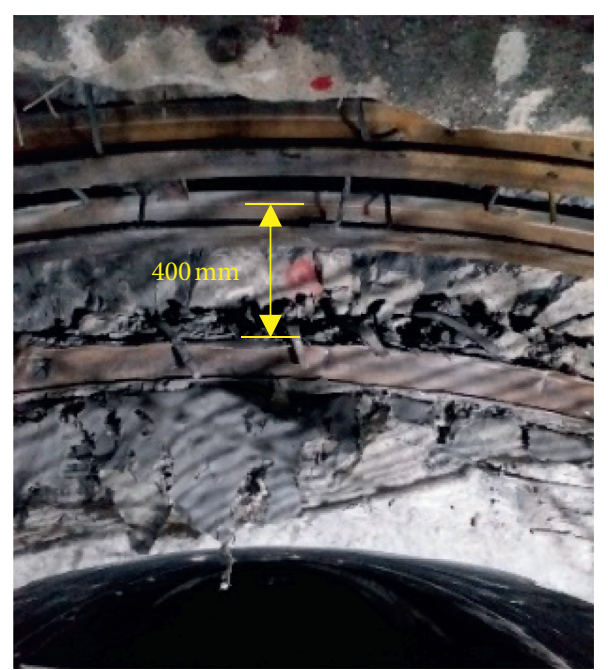

(a)

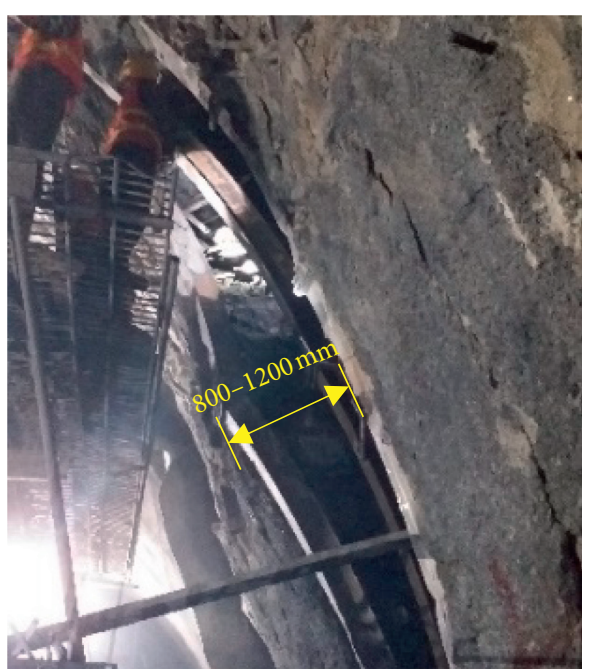

(b)

FIgURE 2: Large deformations of surrounding rocks.

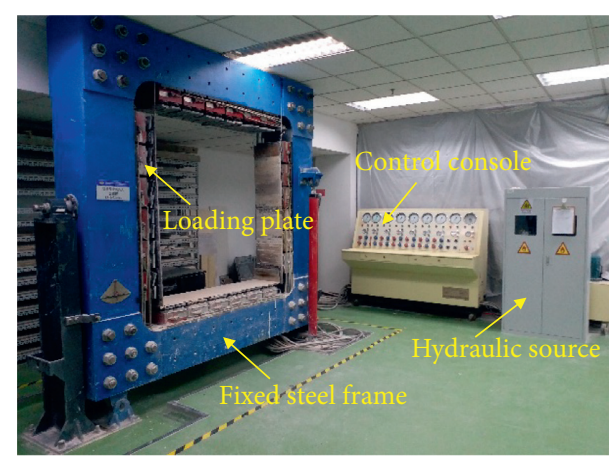

Figure 3: Physical model testing device.

\subsection{Similarity Theory}

3.2.1. Similarity Principles. In order to simulate mechanical behaviors of geotechnical engineering as accurately as possible, some principles derived from the theory of elasticity should be satisfied [27]. They require that the laboratory model should be analogous to the practical prototype in terms of geometries, physical and mechanical properties, and stress and boundary conditions. The ratios of prototype parameters $i_{p}$ to model parameters $i_{p}$ are called the similarity constants, $C_{i}$; that is,

$$
C_{i}=\frac{i_{p}}{i_{p}}
$$

where the parameter $i$ can represent the length $(L)$, stress $(\sigma)$, strain $(\varepsilon)$, displacement $(\delta)$, elastic modulus $(E)$, unit weight $(\gamma)$, Poisson's ratio $(\mu)$, and internal friction angle $(\varphi)$. According to the similarity principles, the following equations between different similarity constants should be satisfied in static geomechanical model tests [28, 29]:

$$
\begin{array}{r}
C_{\sigma}=C_{L} C_{\gamma}, \\
C_{\delta}=C_{L} C_{\varepsilon}, \\
C_{\sigma}=C_{E} C_{\varepsilon}, \\
C_{\varepsilon}=C_{\mu}=C_{\varphi}=1 .
\end{array}
$$

3.2.2. Determination of Similarity Ratios. According to theories of elasticity and rock mechanics [30] the ranges of excavation disturbance zone could be considered as 3-5 times of the opening diameter. The larger number is always selected for high-precision requirement works such as geomechanical model tests and determination of computation domain in numerical simulation, while the smaller number is selected for low-precision work such as in situ stress measurements [30]. In this study, the boundary of excavation influence zone was determined as 5 times of the tunnel diameter.

As mentioned above, the maximum size of testing machine is $1600 \mathrm{~mm}$, and the maximum allowable diameter of the opening in the model is $320 \mathrm{~mm}$. The width of the Minxian tunnel is $12000 \mathrm{~mm}$. Thus, the minimum geometric similarity constant $C_{L}$ is 37.5 . Considering the simulation reliability, actual sizes of Minxian tunnel, and monitoring cells installation, the optimal geometric similarity constant was determined as 40 . The similarity constant of unit weight $C_{\gamma}$ was selected as 1.0. Therefore, other constants could be obtained according to equations (2)-(5), as shown below: 


$$
C_{\sigma}=C_{E}=C_{\delta}=40 .
$$

3.2.3. Similar Materials. The selection of similar materials is one of key factors for successes of physical model tests. Many researchers have studied rock-like materials, of which gypsum has been recognized as a good rock model material and used in many experiments widely [31-33]. Referring to previous results, similar materials in this study were composed of gypsum powder, barite powder, quartz sand, river sand, silicon oil, and water (Figure 4(a)). Among them, the river sand acts as aggregate. The barite powder is one of the most commonly used weighting agents. The gypsum powder was used as cementing agent. The quartz sand was applied to combine the large particles with powders and increase friction of composite materials. The silicon oil was selected as regulator, where the proportion could be adjusted to change the elastic modulus of similar materials.

In order to obtain proper ratios of several materials, a number of standard specimens with different proportions were prepared (Figure 4(b)). Then, uniaxial compression, triaxial compression, and Brazilian tests were conducted in laboratory to measure their mechanical parameters. Finally, the applicable mass ratio was barite powder/river sand/ quartz powder/gypsum powder/water/silicon oil $=1.00 /$ $0.28 / 0.20 / 0.52 / 0.48 / 0.04$. The comparison of various parameters between target and actual similar materials was shown in Table 1, and general good agreements could be found.

\subsection{Test Design}

3.3.1. Physical Model. The cross section of mileage YK235 + 495 in the right tunnel was selected as prototype of the physical model, where the serious deformation and large-scale failure of surrounding rocks occurred. As shown in Figure 5(a), there was a fault throughout the model with the attitude of $90^{\circ} \angle 70^{\circ}$. The occurrence of rock layers on left side of the fault was also $90^{\circ} \angle 70^{\circ}$, while the occurrence on the right side was $270^{\circ} \angle 40^{\circ}$. The simulated rock mass was carbonaceous slate with developed foliations. The tunnel was located at the center of the model, and the shape of cross section was horseshoe. Radii of upper and bottom circular arcs were $150 \mathrm{~mm}$ and $200 \mathrm{~mm}$, respectively. The maximum width and height of the tunnel were $300 \mathrm{~mm}$ and $255 \mathrm{~mm}$, respectively.

3.3.2. Stress Boundary Conditions. The thickness of the overlying rock mass at the selected cross section was about $200.2 \mathrm{~m}$, and the thickness of rock mass simulated in the physical model was $24.2 \mathrm{~m}$. Therefore, the load applied to the model from the vertical direction was the gravity caused by the overlying rock mass with a thickness of $176 \mathrm{~m}$. Considering the stress similarity ratio, the vertical stress applied to the model should be $0.11 \mathrm{MPa}$; and the horizontal stress should be $0.14 \mathrm{MPa}$, since the lateral stress coefficient was 1.3. Stress boundary conditions of the physical model were shown in Figure 5(a). Because the stress fields of the physical model violate the precise conditions of plane strain, the physical model in this study was considered as being in a quasi-two-dimensional plane strain state.

3.3.3. Excavation Plan. In order to simulate the actual excavation process as real as possible, the cross section of the tunnel in the model was divided into four areas (Figure 5(b)), namely, the first bench, the second bench, the third bench, and the inverted arc. The heights of four areas were $75 \mathrm{~mm}, 60 \mathrm{~mm}, 60 \mathrm{~mm}$, and $60 \mathrm{~mm}$, corresponding to the actual heights of $3.0 \mathrm{~m}, 2.4 \mathrm{~m}, 2.4 \mathrm{~m}$, and $2.4 \mathrm{~m}$, respectively. The actual tunnelling footage was $1.2 \mathrm{~m}$; therefore, the corresponding excavation footage in the model was $30 \mathrm{~mm}$, as shown in Figure 5(c). The actual delay distance between the next and previous benches was $2.4 \mathrm{~m}$, and the corresponding distance in the model was $60 \mathrm{~mm}$. Finally, there would be a total of four stages with 19 steps represented by E1-E19 in the whole excavation process (Figure 5(c)). (a) In the first stage, only the first bench would be excavated where steps E1 and E2 would be removed. (b) In the second stage, the first and second benches would be excavated simultaneously where steps E3 and E4 would be carried out. (c) In the third stage, the first, second, and third benches would be excavated during each tunnelling cycle where steps E5 and E6 would be conducted. (d) In the fourth stage, the first bench, the second bench, the third bench, and the inverted arc would be synchronously excavated where steps E7-E19 would be implemented.

\subsubsection{Monitoring Scheme}

(1) Monitoring Design. Stress and deformation of surrounding rocks were the key monitoring information to investigate the deformation and failure mechanism of the tunnel during the excavation process. As shown in Figure 6, a monitoring section was designed to measure strains of some positions in the surrounding rocks. The distance between the monitoring section and model surface was $50 \mathrm{~mm}$ along the tunnel axial direction.

There were ten monitoring lines along the radial direction of the tunnel. Among them, three lines were set up, respectively, for the first bench and the inverted arc numbered as F1, F2, F3, I1, I2, and I3. F1 and I1 were located at 45 degrees to the left of the tunnel, and F3 and I3 were symmetrical with them about the center line of the tunnel. Two lines were set up, respectively, for the second and third benches marked as $\mathrm{S} 1, \mathrm{~S} 2, \mathrm{~T} 1$, and $\mathrm{T} 2$. Then, four monitoring rings labeled as $\mathrm{A}, \mathrm{B}, \mathrm{C}$, and $\mathrm{D}$ were set up along the circumferential direction of the tunnel (Figure 6). Their radii were $200 \mathrm{~mm}, 300 \mathrm{~mm}, 400 \mathrm{~mm}$, and $500 \mathrm{~mm}$, respectively, corresponding to $2 \mathrm{~m}, 6 \mathrm{~m}, 10 \mathrm{~m}$, and $14 \mathrm{~m}$, respectively, from the tunnel free surface in real engineering. The intersection points of ten radial monitoring lines and four circumferential rings were determined as strain monitoring positions. For example, F2-B represented the monitoring point located at the position that was 45 degrees to the left of the tunnel and $300 \mathrm{~mm}$ from the tunnel surface. Finally, 


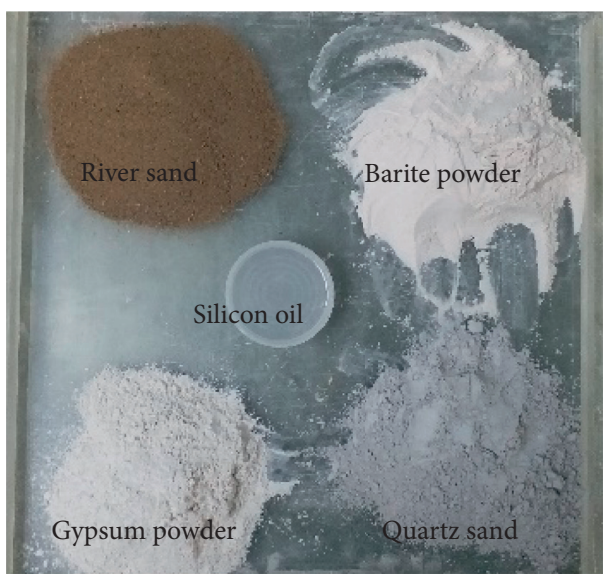

(a)

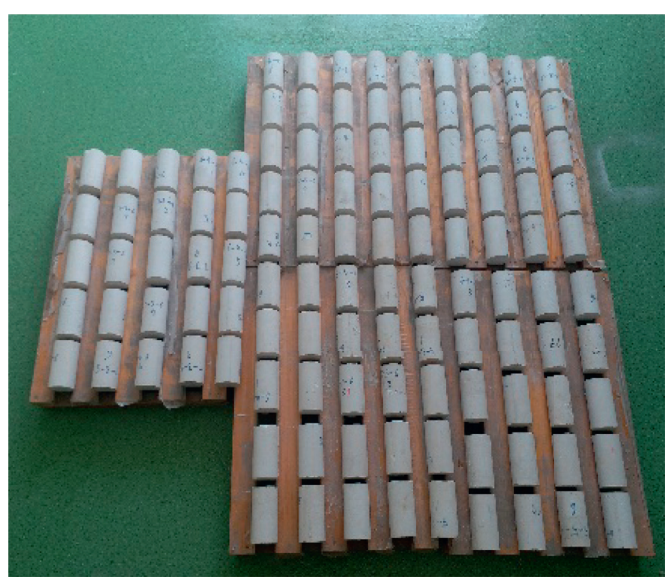

(b)

Figure 4: Similar materials. (a) Components of similar materials and (b) standard specimens of different proportions.

TABle 1: Physical and mechanical parameters of the real rock and the analogue materials.

\begin{tabular}{|c|c|c|c|c|c|c|c|}
\hline & $\rho\left(\mathrm{kg} / \mathrm{m}^{3}\right)$ & UCS (MPa) & $\sigma_{t}(\mathrm{MPa})$ & $c(\mathrm{MPa})$ & $E(\mathrm{GPa})$ & $\mu$ & $\phi\left(^{\circ}\right)$ \\
\hline Real rock & 2460 & 35.74 & 2.26 & 7.15 & 28.91 & 0.16 & 32 \\
\hline Target similar material & 2460 & 0.89 & 0.06 & 0.72 & 0.18 & 0.16 & 32 \\
\hline Actual similar material & 2250 & 1.03 & 0.08 & 0.84 & 0.22 & 0.19 & 34 \\
\hline
\end{tabular}

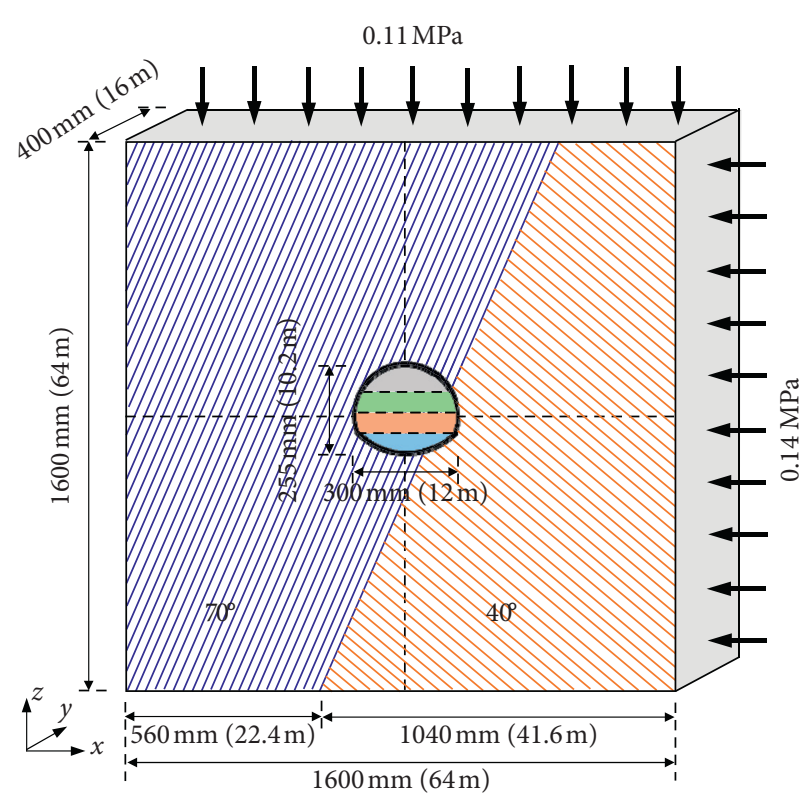

(a)

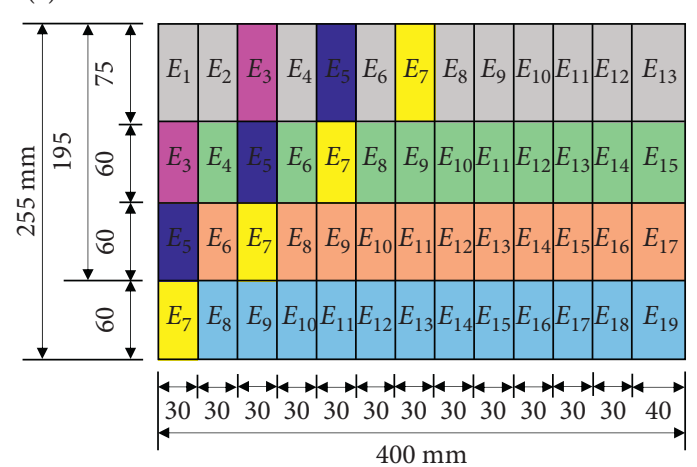

(c)

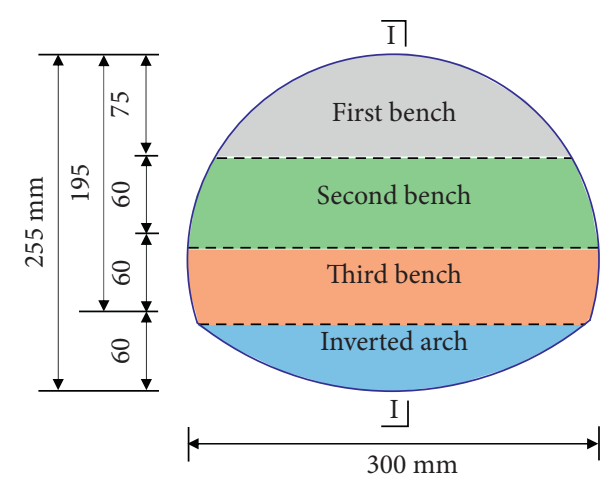

(b)

Figure 5: Physical model design: (a) layout of physical model, (b) three-bench tunnelling method in the tunnel face, and (c) tunnelling footage and steps (II-I section). 


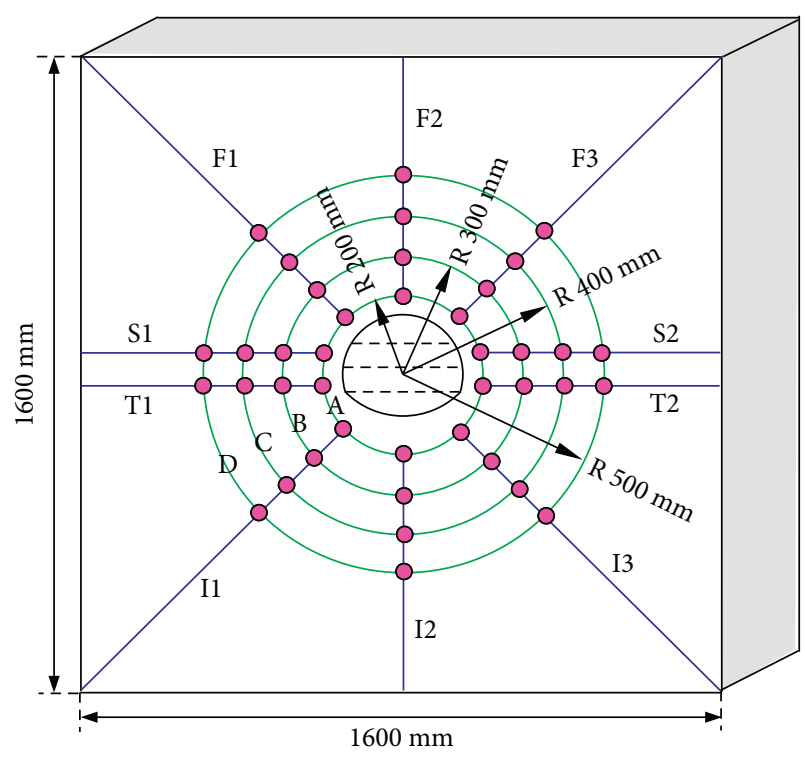

FiguRe 6: Layout of monitoring section $(y=5 \mathrm{~cm})$ and points.

there were a total of 40 strain measurement points in the model.

(2) Monitoring Methods

(a) Digital image correlation method: digital image correlation (DIC) technology developed by $[34,35]$ is a noncontact optical measurement method for full-field deformation based on digital image processing and numerical calculation. The displacements or strains field of medium surface is calculated by analyzing the deformations and displacements of information carrier (e.g., metal surface texture or speckle with the random distribution of gray value) in two images before and after deformation [36, 37]. Typical twodimensional DIC system mainly consists of light source, CCD camera, and image analysis software. In order to meet the requirements of the test for light intensity and long-time stabilization, two high light intensity LED cold-light lamps were chosen as the lighting source. The CCD camera was used to record the speckle information in overall excavation process. The camera model in the experiment is Man-ta-G-505 produced by AVT in Germany, whose resolution is 5 megapixels $(2448 \times 2050)$ and maximum frame rate is 15 FPS. In addition, a high-performance fixed-focal lens $(12 \mathrm{~mm})$ from Computar in Japan was added to the camera. The camera was connected to the image acquisition software named MI-Grabber developed by the company Match ID to obtain and store highquality images. The displacement precision measured by this image acquisition system is $0.001 \sim 0.01$ pixel.

(b) Strain acquisition system: two-YSV-8360-staticstrain tester was used to record strains of monitoring points. The data acquisition frequency of the tester is $512 \mathrm{~Hz}$, and strain measurement range is $\pm 30000 \mu \varepsilon$.

\subsection{Test Process}

3.4.1. Preparation of Finite Elementary Slabs. As shown in Figure 7, firstly, barite powder, river sand, quartz sand, gypsum powder, and water were mixed in proportion. Secondly, the mixed material was stirred well and poured into an acrylic mold with the sizes of $40 \mathrm{~cm} \times 40 \mathrm{~cm} \times 2 \mathrm{~cm}$ (length $\times$ width $\times$ height). After 30 minutes, the elementary slab was solidified and removed from the mold. Then, it was sun-cured briefly to evaporate water quickly. It is noted that the drying time should not be too long in case of the slab cracking. Finally, the elementary slab was placed indoors for air drying. A total of 370 pieces of finite elementary slabs were prepared in this test.

3.4.2. Model Construction. According to the test design, slabs were numbered and piled up piece by piece. For example, L5-2 referred to the second slab in the fifth layer to the left of the fault, and R7-3 referred to the third slab in the seventh layer to the right of the fault. The construction process of the physical model is shown in Figure $7(\mathrm{~b})$.

For the simulation of tunnel face, the general method is piling up intact elementary slabs firstly and then excavating the cross section of the tunnel by some machine tool during the test $[19-24,26]$. It is convenient to build the model; however, it is difficult and time-consuming to control the cross section of the tunnel and tunnelling footage during the test. In this study, elemental slabs in the range of tunnel face were cut firstly into small blocks whose widths were the same with each excavation footage; then, they were piled up together. The excavation step would be conducted by removing specific small blocks.

3.4.3. Embedment of Strain Bricks. As mentioned before, stress state can be treated as quasi-plane strain. The strain and stress parallel to the tunnel section can only be monitored and analyzed ( $x-z$ plane). According to the theory of elasticity, three strains along three directions should be known to obtain planar principal strains or stresses. Therefore, strain rosettes with directions of $0^{\circ}, 45^{\circ}$, and $90^{\circ}$ were used as the strain measuring cell (Figure $7(\mathrm{c})$ ). According to the monitoring plan, strain bricks were positioned and buried at the monitoring points on the specific numbered elementary slabs.

3.4.4. Preparation of Speckle Field. The deformation information carrier is an important medium for deformation measurement by DIC method. Its quality is related to the accuracy of measurement results. At present, there are mainly two kinds of carriers: natural texture of material surface and artificial preparation of speckle field. The carrier in this test is artificial speckle spots prepared on the surface of the model. According to Munoz et al. [36], the contrast of speckle grain should be obvious, and the calculation error is small when the size of speckles is $5-10$ pixels. The area of speckle field in this test is 2.56 million $\mathrm{mm}^{2}$ $(1600 \mathrm{~mm} \times 1600 \mathrm{~mm})$, and the corresponding size of each pixel point is about $0.5 \mathrm{~mm} \times 0.5 \mathrm{~mm}$. So, the size of each speckle should be $2.5-5.0 \mathrm{~mm}$ (Figure $7(\mathrm{~d})$ ).

3.4.5. Monitoring Equipment Debugging. Before the excavation, monitoring devices debugging was carried out. All strain gauges were numbered and connected to two strain 


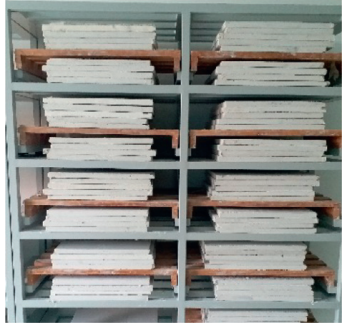

(a)

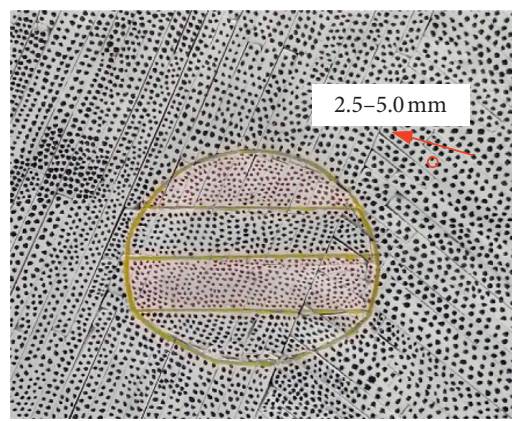

(d)

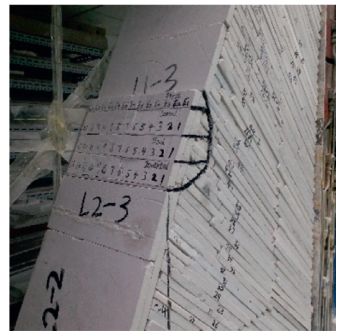

(b)

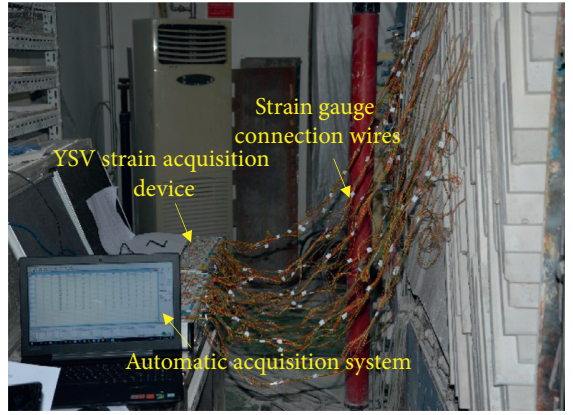

(e)

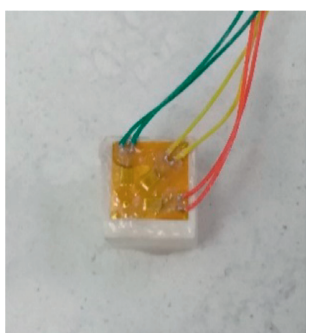

(c)

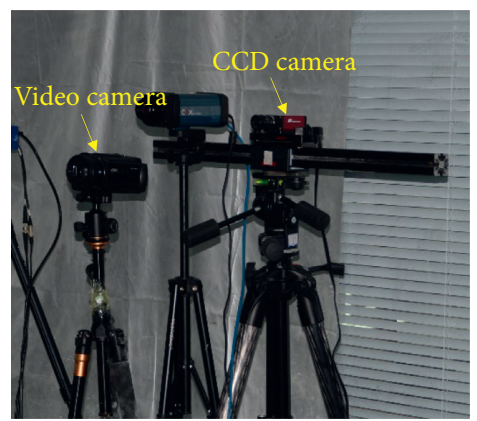

(f)

FIGURE 7: Testing process: (a) preparation of finite elementary slabs, (b) construction of the model, (c) embedment of strain gauges, (d) preparation of speckles field, (e) debugging of strain acquisition system, and (f) debugging of noncontact monitoring instruments.

acquisition instruments (Figure 7(e)). The CCD camera used for speckle imaging was connected to the automatic imaging acquisition system (Figure 7(f)). In addition, a $4 \mathrm{~K}$ HD video camera was used to record the whole process.

3.4.6. Loading. According to the designed stress loading path, the vertical load was loaded to $0.11 \mathrm{MPa}$ gradually and the horizontal load to $0.14 \mathrm{MPa}$. It was the initial stress state and had been maintained for $60 \mathrm{~min}$.

3.4.7. Tunnelling and Monitoring. When the duration time of initial stress state was reached, all monitoring devices started to work. The imaging frequencies of CCD industrial camera and infrared camera were 1 time/10 s. Then, the tunnel would be excavated gradually according to the designed excavation plan.

\section{Test Results and Analysis}

\subsection{Evolution of Surrounding Rocks Deformation}

4.1.1. First Stage. After the completion of steps E1 and E2 (Figure 8(a)), the initial stress carried by the rock mass in the first bench transferred to the surrounding rocks, and the stress concentration occurred. Initial fissures and weak joints cracked under tensile stresses caused by bending deformation (Figure 8(b)). There was the phenomenon of chip off-falling at the vault and right shoulder due to the coalescence of local fissures (Figure 8(c)). Figure 8(d) shows chip off-falling of the surrounding rocks on the right shoulder in the tunnel field.
4.1.2. Second Stage. In steps E3 and E4 (Figure 9(a)), the first and the second benches were both excavated. The area of exposed rock slab on left side of the tunnel increased, and its antibend performance declined. The thin rock layer on left side of the tunnel was similar to thin plate, and several rock layers were bent under concentrated stresses, which resulted in discontinuous deformation and separation due to different deformation stiffness between different rock strata (Figure 9(b)). The contact surface between the third bench and the bottom rock mass also cracked under horizontal compression stress due to the disappearance of limit caused by the overlying rock mass, which resulted in the slight floor heave (Figure 9(c)). Moreover, the effects of excavation unloading and stress redistribution were also significant. Local sidewall spalling and large-area cracking occurred on left side of the tunnel due to cracks expanding and coalescence under high concentrated stress (Figure 9(d)). Figure 9(e) shows large area damage on left side surface of the surrounding rocks in the tunnel field.

4.1.3. Third Stage. During this stage (E5 and E6), the full cross section of the tunnel above the ground would be formed (Figure 10(a)). There was serious damage on left side of the tunnel such as a wide range of wall spalling and cracking (Figure 10(b)). The broken rock lump fell from left shoulder of the tunnel (Figure 10(c)). The rock mass near the fault was broken due to the mutual squeezing of angular unconformable rock strata (Figure 10(e)). Figure 10(d) and Figure 10(f) show the local collapse of surrounding rocks on left shoulder and broken rock mass near the fault in the tunnel field, respectively. 


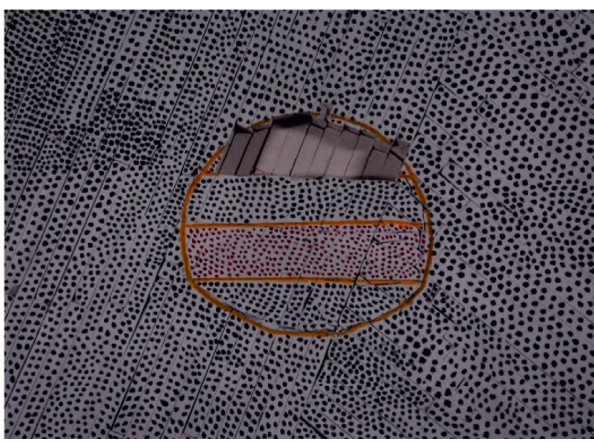

(a)

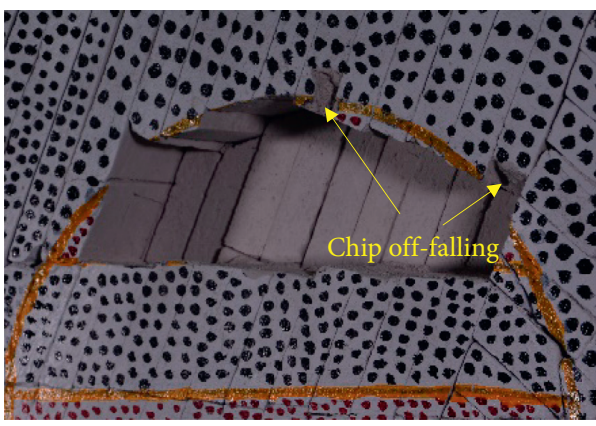

(c)

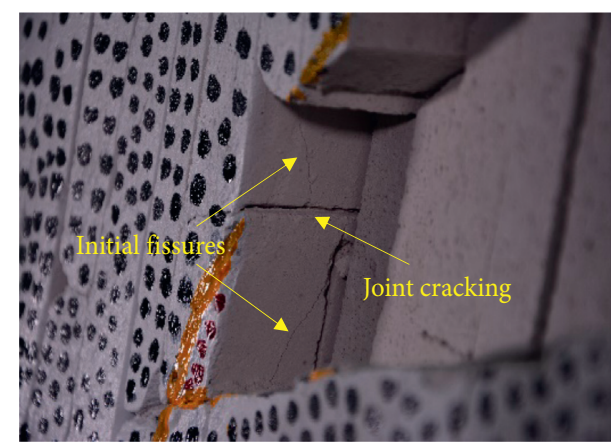

(b)

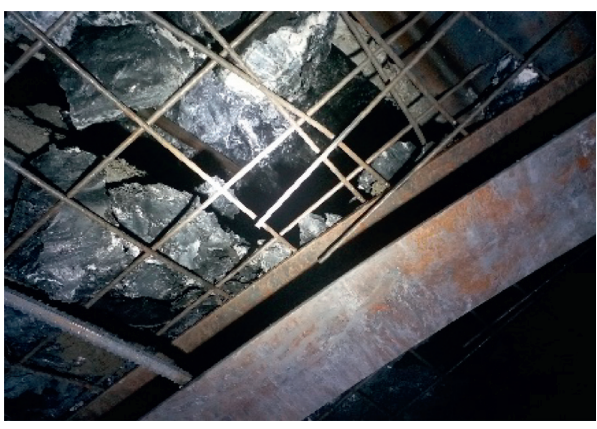

(d)

FIgURE 8: First excavation stage (E1 and E2) and deformations of surrounding rocks.

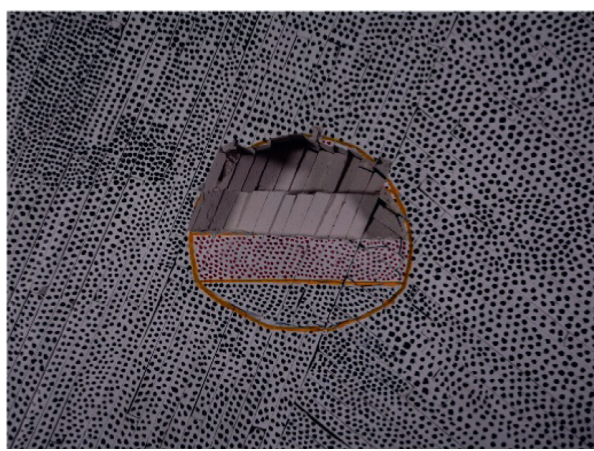

(a)

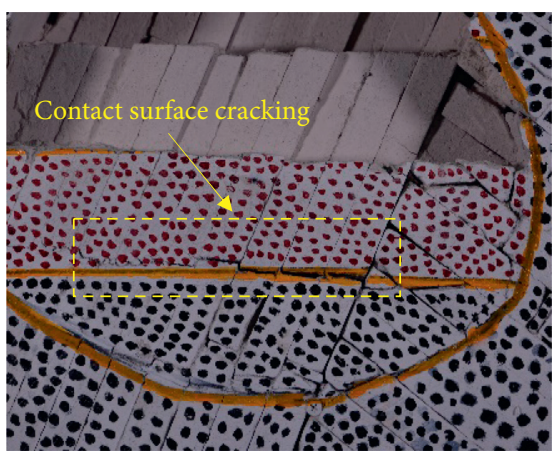

(c)

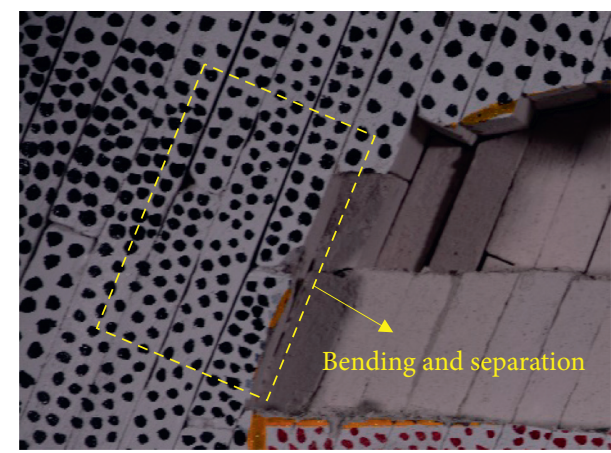

(b)

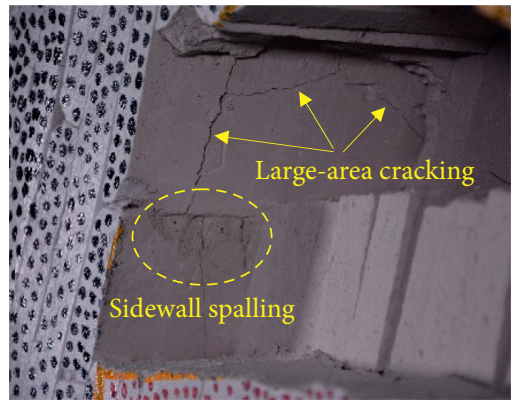

(d)

Figure 9: Continued. 


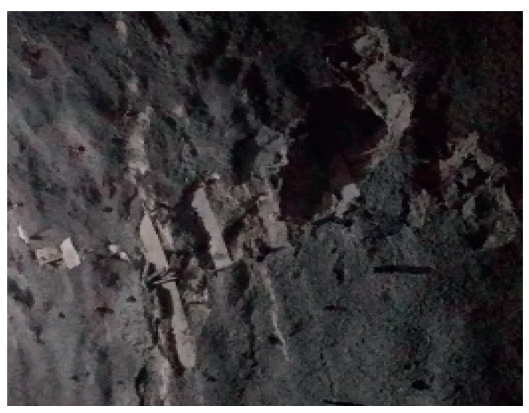

(e)

Figure 9: Second excavation stage (E3 and E4) and deformations of surrounding rocks.

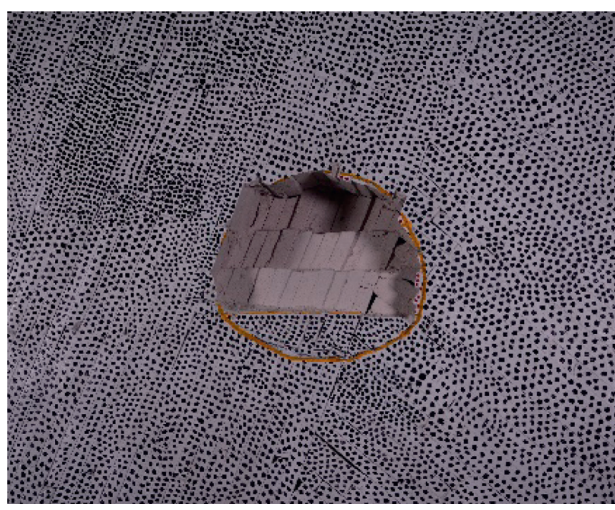

(a)

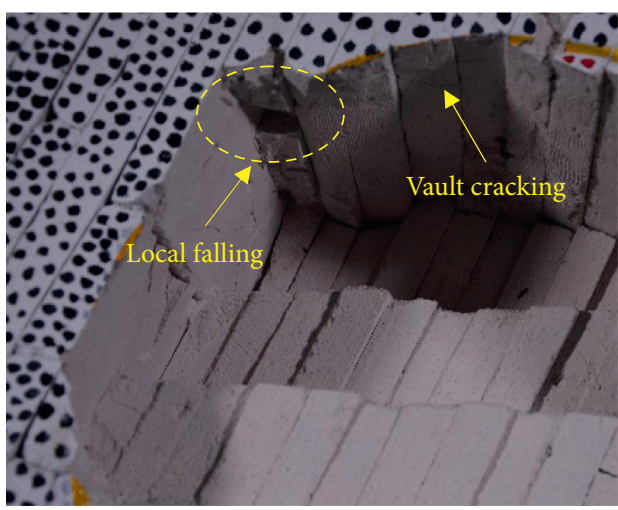

(c)

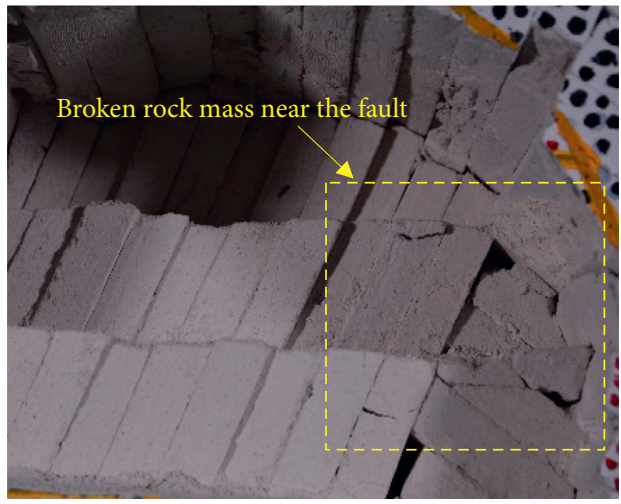

(e)

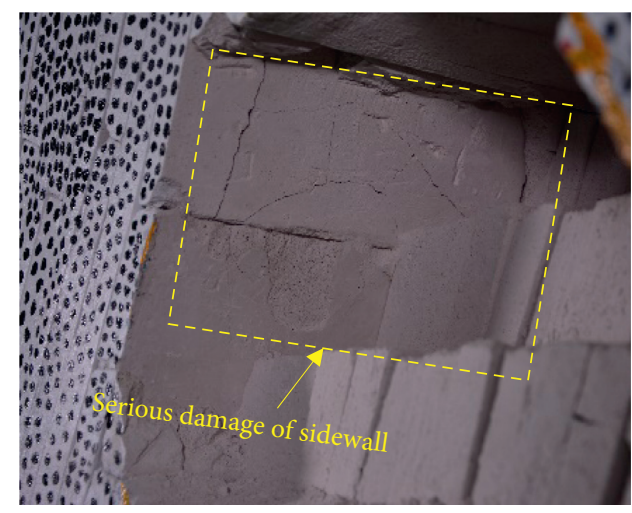

(b)

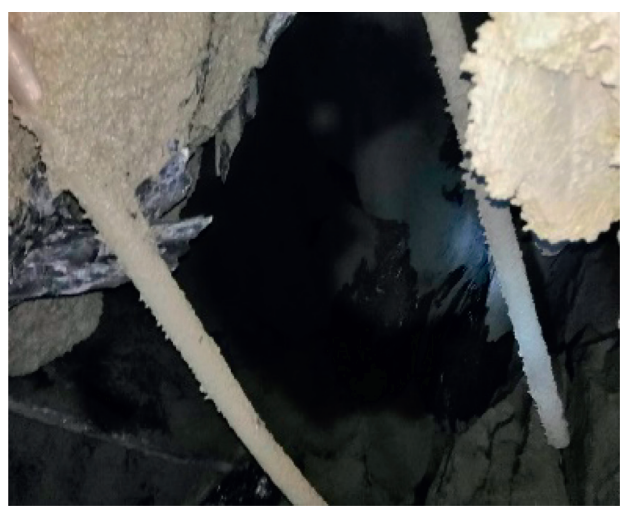

(d)

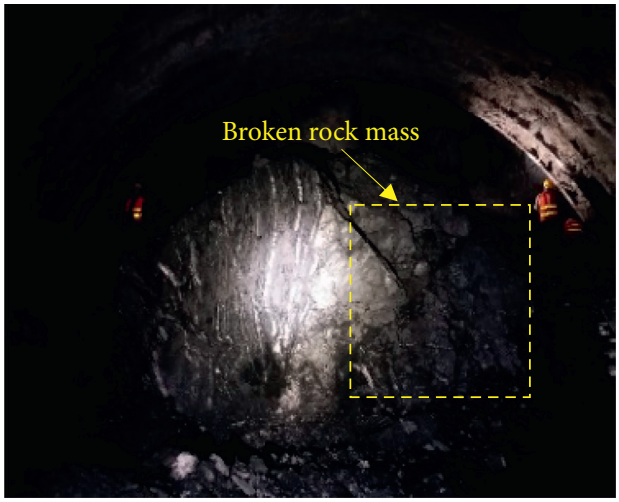

(f)

FIGURE 10: Third excavation stage (E5 and E6) and deformations of surrounding rocks. 
4.1.4. Fourth Stage. In step E7 of the fourth stage (Figure 11(a)), the full cross section of the tunnel was excavated, which included the first, second, and third benches and the inverted arc area, in which the maximum exposed area of the free surface was reached and the effect of stress redistribution was most significant. The exposed thin rock slabs on both sides of the tunnel were severely bent (Figure 11(b)). All free surfaces (left, top, and right) of the tunnel were seriously damaged, and there were several obvious circumferential fractures (Figures 11(c) and 11(d)). Figure 11(e) shows the actual large-scale circumferential fractures in the tunnel field. The overlying strata caved suddenly along the fault and foliation after some unstable rock blocks at the top of the tunnel dropping down (Figure 11(a)). It means that the tunnel failed totally in this step.

\subsection{Strain Analysis}

4.2.1. Strains around the Tunnel. The radial convergent deformations of the surrounding rocks around the tunnel (taking the monitoring circle $\mathrm{A}$ as an example) during the overall process were shown in Figure 12.

(a) The deformations of surrounding rock around the tunnel increased gradually with the development of time due to the increase of exposed free surface. There were different increments at different positions in each excavation step. (b) Before large-scale collapse appeared, the maximum radial strain occurred $(0.022 \%)$ at left waist of the second bench (point S1-A) due to the bending deformation under the squeezing stress. The effects of stress redistribution and excavation unloading could result in bending deformation of the rock slabs and radial movement of monitoring points. In particular, there were bigger deformation increments in steps E5, E6, and E7, which was also consistent with the deformation characteristics of surrounding rocks. (c) The radial strains of surrounding rocks around the first bench (F1-A, F2-A, and F3-A) were in the range of $0.010 \% \sim 0.012 \%$. Among them, the largest deformation took place at the vault (F2-A) due to the shearing of two rock layers, and the smallest deformation occurred at the point near the fault (F3-A) due to confinement of angular unconformable rock strata on both sides of the fault. (d) The radial strains of monitoring points (I1-A, I2-A, and I3-A) in bottom surrounding rocks were relatively small, especially in steps E1E4. During step E5, the contact surface between inverted rock mass and the lower surrounding rocks cracked under the horizontal compression and tensile stress. As a result of pressure relief, the radial strains of bottom surrounding rocks suddenly increased, and the strains' increments became larger significantly in steps E6 and E7.
4.2.2. Strains in Different Depths of Surrounding Rocks. The evolution process of radial deformation in different depths of the surrounding rocks (taking the monitoring line F1 as an example) is shown in Figure 13.

(a) The radial strains of surrounding rocks increased continuously along with enlargement of exposed surface area of the tunnel. (b) There was significant difference between different depths of surrounding rocks in total radial strains. The radial strains of monitoring points decreased with the increase of distance from excavation boundary; that is, $\varepsilon_{F 1-A}>\varepsilon_{F 1-B}>\varepsilon_{F 1-C}>\varepsilon_{F 1-D}$. (c) The actual distances from points $C$ and $D$ to free surface of the tunnel were $10 \mathrm{~m}$ and $14 \mathrm{~m}$, respectively, and the corresponding radial strains were $0.006 \%$ and $0.005 \%$. It means that the deformations of surrounding rocks in this range were not significantly affected by the excavation. In the field, the range of excavation loose circle of the surrounding rocks measured by acoustic wave testing was $9 \mathrm{~m} \sim 12 \mathrm{~m}$ (Figure 14), which shows that the results of physical model test and the field measurement were similar and closed. (d) There was some sudden increase of strains in surrounding rocks after every excavation step, which illustrated that the mechanical responses of surrounding rocks were not instantaneous but required some time until the redistributed stress becomes balanced. (e) The influences of different excavation steps on surrounding rocks strains were also different. Among them, the increases of strains in step E5 were largest, since the area of tunnel section above the ground reached the maximum, followed by step E7, where only partial data before the total collapse and failure could be obtained.

\subsection{Stress Analysis}

4.3.1. Principal Stresses Calculation. In order to analyze stress evolution of surrounding rocks during the excavation, the maximum principal stresses of monitoring points were calculated firstly based on the measured strains according to the strain coordinate transformation formulas and Hooke's law in elasticity theory [38]. The installation angles of strain flowers on both sides of the fault were shown in Figure 15.

The relationships between three measured strains of each point and strains along $x$ and $y$ directions on left side of the fault are

$$
\varepsilon_{70}=\varepsilon_{x, l}\left(\cos ^{2} 70\right)+\varepsilon_{y, l}\left(\sin ^{2} 70\right)+\gamma_{x y, l}(\sin 70 \cos 70)
$$

$\varepsilon_{115}=\varepsilon_{x, l}\left(\cos ^{2} 115\right)+\varepsilon_{y, l}\left(\sin ^{2} 115\right)+\gamma_{x y, l}(\sin 115 \cos 115)$, 


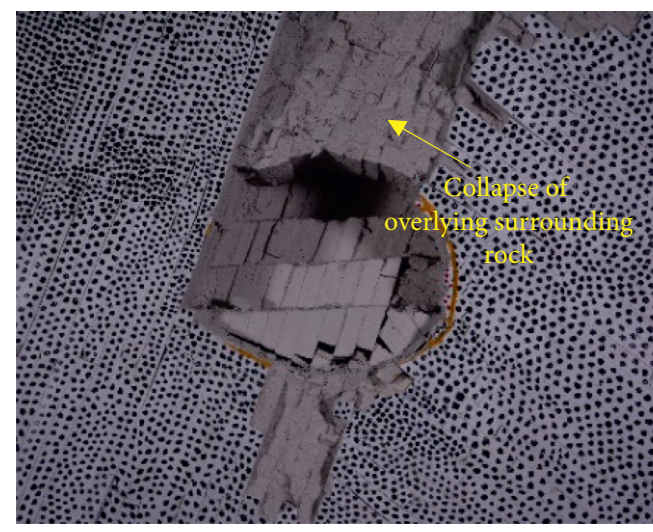

(a)

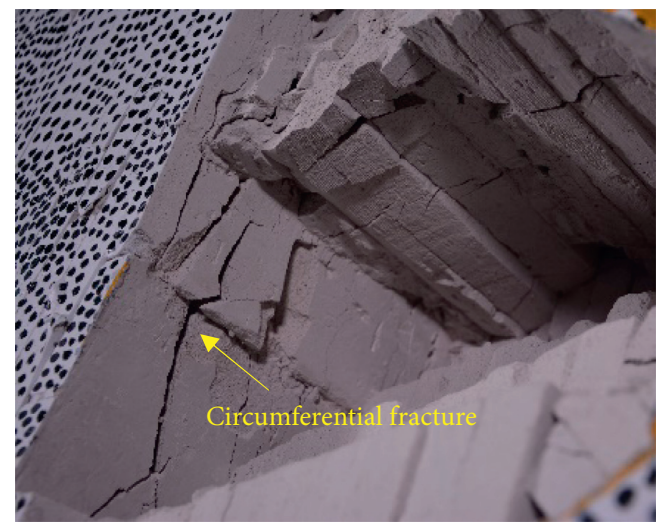

(c)

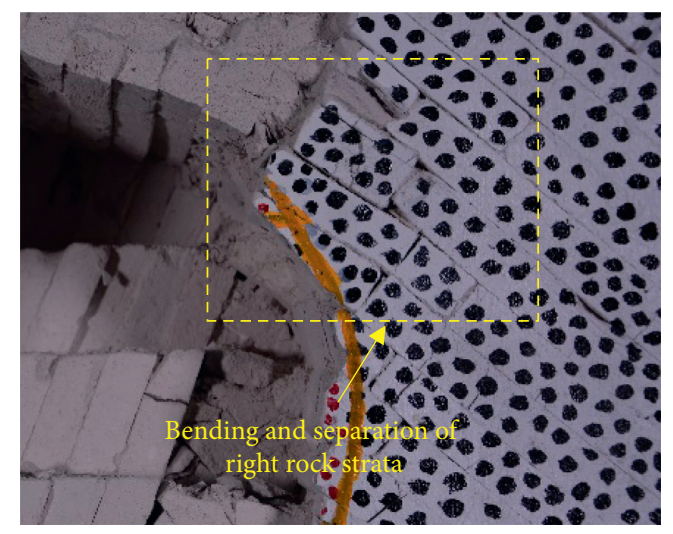

(b)

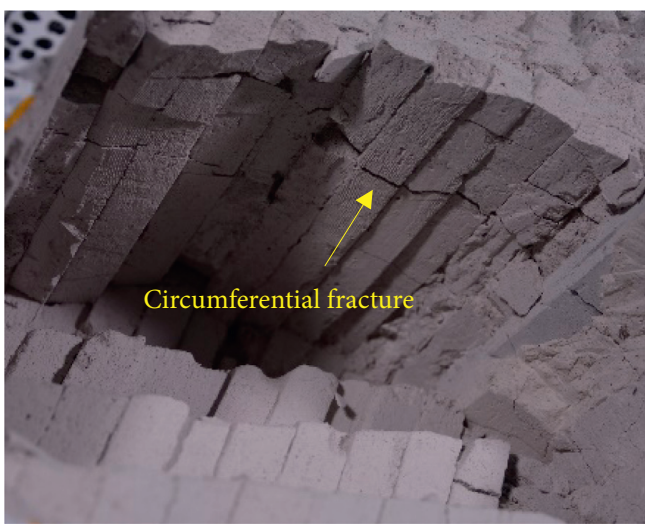

(d)

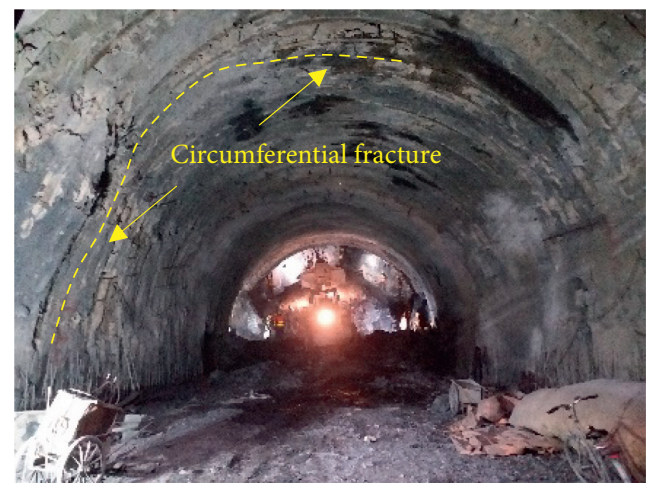

(e)

Figure 11: Excavation step E7 and deformations of surrounding rocks.

$\varepsilon_{160}=\varepsilon_{x, l}\left(\cos ^{2} 160\right)+\varepsilon_{y, l}\left(\sin ^{2} 160\right)+\gamma_{x y, l}(\sin 160 \cos 160)$,

where $\varepsilon_{70}, \varepsilon_{115}$, and $\varepsilon_{160}$ are measured strains represented by red, yellow, and green strain gauges of left strain flower, respectively; $\varepsilon_{x, l}, \varepsilon_{y, l}$, and $\gamma_{x y, l}$ are normal and shearing strains along horizontal and vertical direction of the model. Then plane principal strains of the point can be obtained according to the following formulas:

$$
\begin{aligned}
& \varepsilon_{1, l}=\frac{1}{2}\left(\varepsilon_{x, l}+\varepsilon_{y, l}\right)+\frac{1}{2} \sqrt{\left(\varepsilon_{x, l}-\varepsilon_{y, l}\right)^{2}+\gamma_{x y, l}^{2},} \\
& \varepsilon_{2, l}=\frac{1}{2}\left(\varepsilon_{x, l}+\varepsilon_{y, l}\right)-\frac{1}{2} \sqrt{\left(\varepsilon_{x, l}-\varepsilon_{y, l}\right)^{2}+\gamma_{x y, l}^{2}},
\end{aligned}
$$

$\tan 2 \theta_{l}=-\frac{\gamma_{x y}}{\varepsilon_{x}-\varepsilon_{y}}$, 


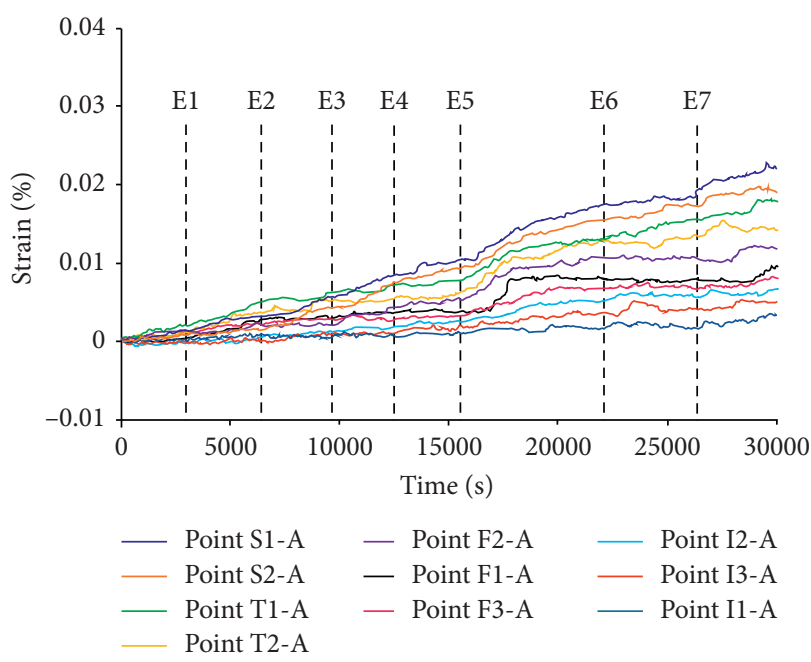

(a)

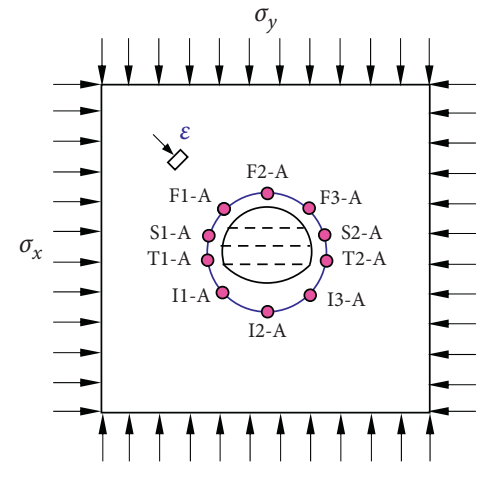

(b)

FIGURE 12: Evolution of surrounding rocks strains around the tunnel: (a) the curves of radial strain versus time and (b) taking the monitoring circle A around the tunnel as an example.

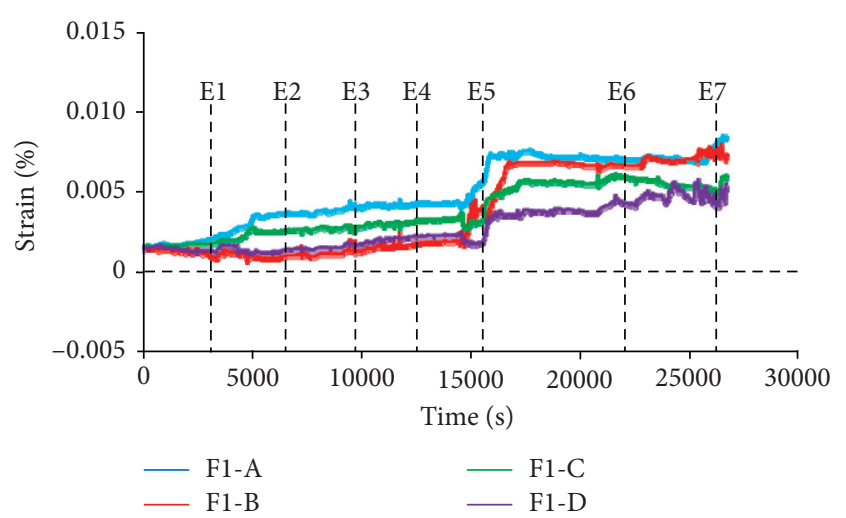

(a)

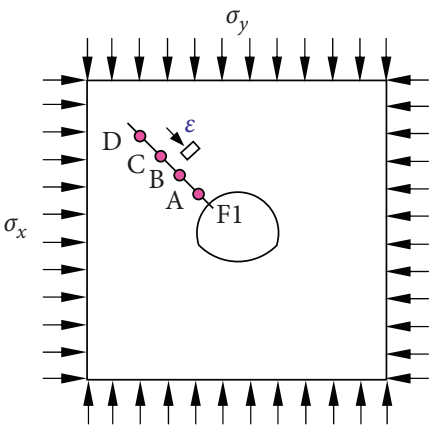

(b)

FIGURE 13: Evolution of surrounding rocks strains in different depths: (a) the curves of radial strain versus time and (b) taking the monitoring line F1 at left shoulder of the tunnel as an example.

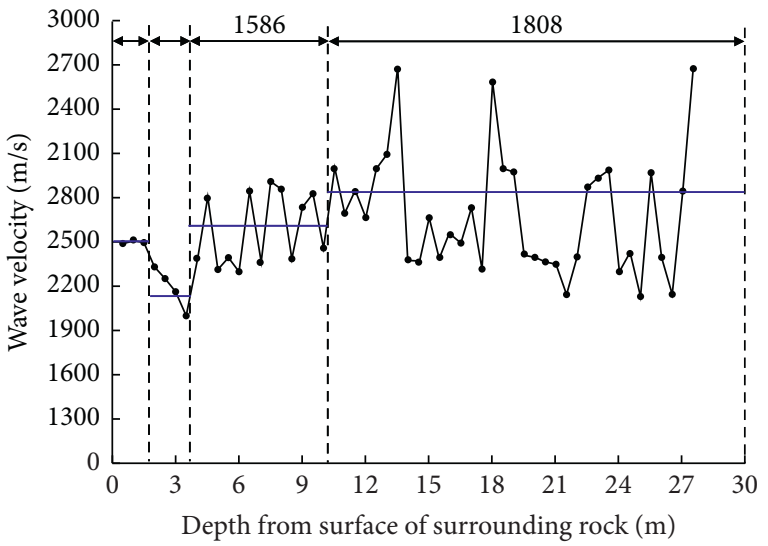

FIGURE 14: In situ measured result of acoustic wave testing at YK235 + 280 in the right tunnel. where $\varepsilon_{1, l}$ and $\varepsilon_{2, l}$ are maximum and minimum plane principal strains, respectively; $\theta_{l}$ is the angle between maximum principal strain and positive direction of $x$-axis. Finally, two principal stresses of the point can be acquired by the following equations:

$$
\begin{aligned}
& \sigma_{1}=2 G \varepsilon_{1}+\lambda\left(\varepsilon_{1}+\varepsilon_{2}\right), \\
& \sigma_{2}=2 G \varepsilon_{2}+\lambda\left(\varepsilon_{1}+\varepsilon_{2}\right),
\end{aligned}
$$

where $\sigma_{1}$ and $\sigma_{2}$ are maximum and minimum plane principal stresses, respectively; $\lambda$ and $G$ are Lame constants, which can be calculated by elasticity modulus $E$ and Poisson's ratio $v$ as 


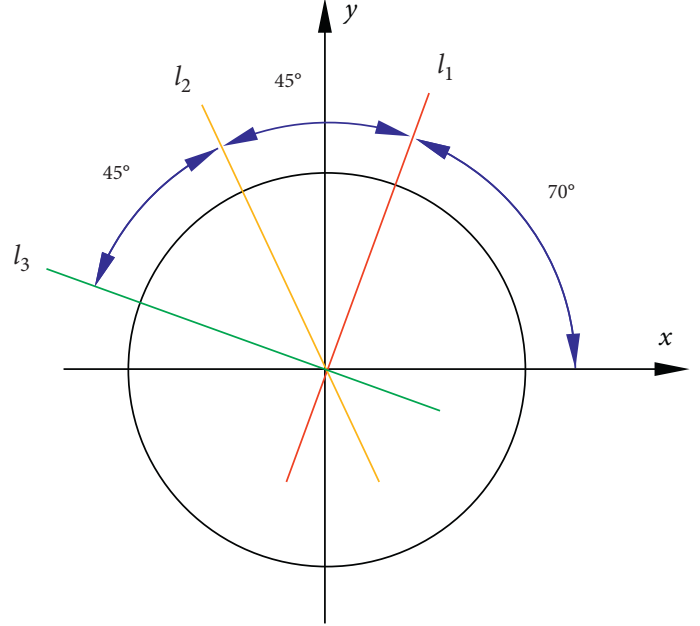

(a)

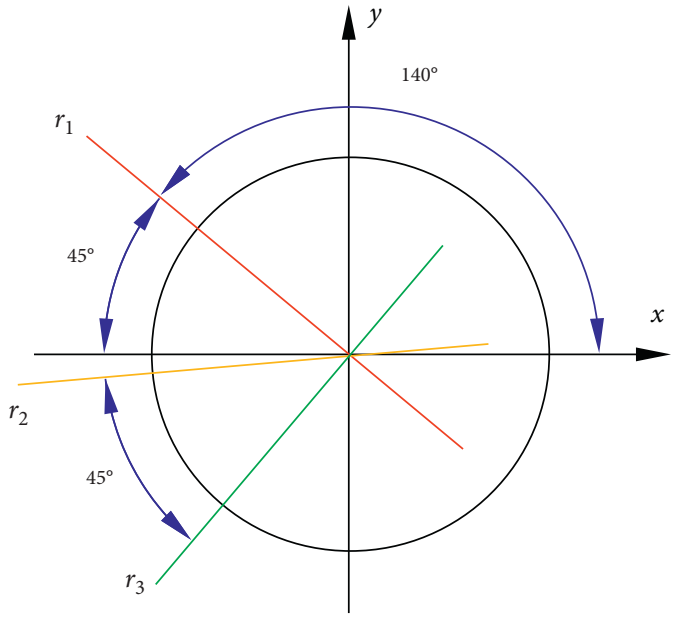

(b)

Figure 15: Installation angles of strain flowers on both sides of the fault: (a) left side and (b) right side.

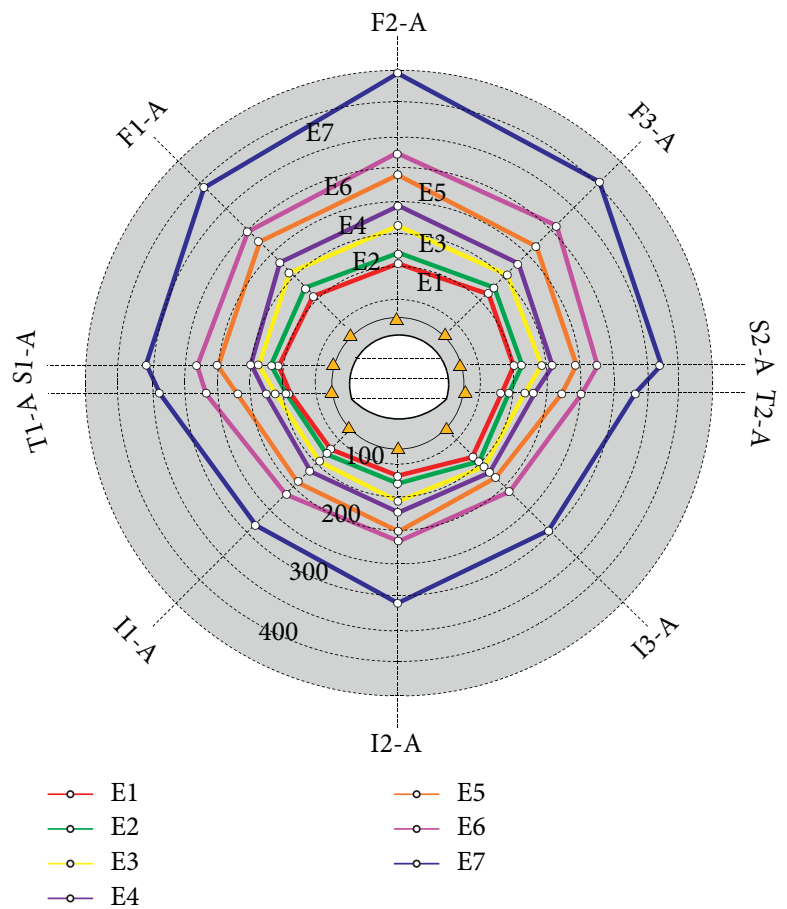

(a)

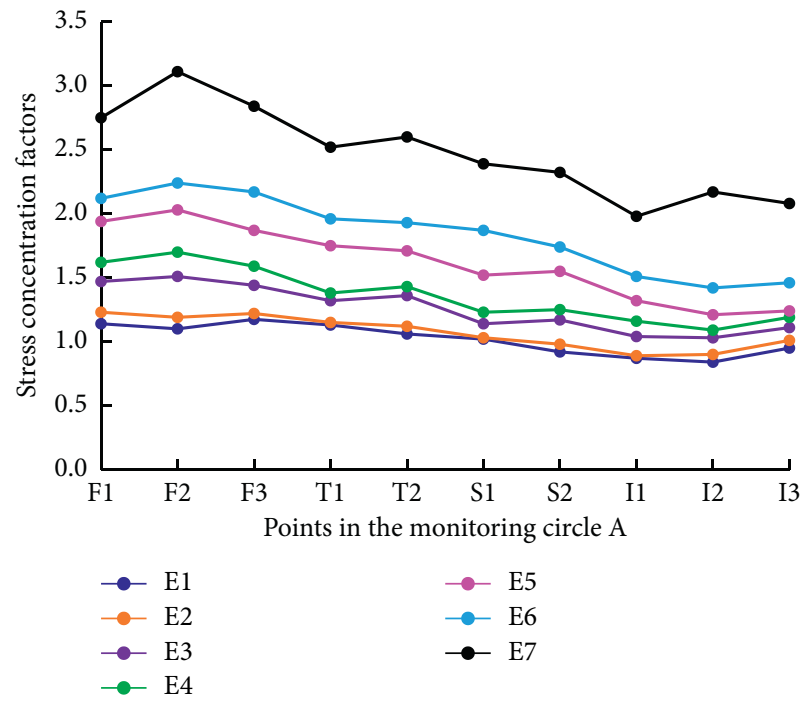

Figure 16: (a) Temporal and spatial distribution of maximum principle stresses of the monitoring circle A around the tunnel; (b) evolution of stress concentration factors of the monitoring points.

$$
\begin{aligned}
& \lambda=\frac{E v}{(1+v)(1-2 v)}, \\
& G=\frac{E}{2(1+v)} .
\end{aligned}
$$

The relationships between three measured strains of left side points of the fault and strains of $x$ and $y$ directions are

$$
\begin{aligned}
\varepsilon_{140}= & \varepsilon_{x, l}\left(\cos ^{2} 140\right)+\varepsilon_{y, l}\left(\sin ^{2} 140\right) \\
& +\gamma_{x y, l}(\sin 140 \cdot \cos 140), \\
\varepsilon_{185}= & \varepsilon_{x, l}\left(\cos ^{2} 185\right)+\varepsilon_{y, l}\left(\sin ^{2} 185\right) \\
& +\gamma_{x y, l}(\sin 185 \cdot \cos 185),
\end{aligned}
$$




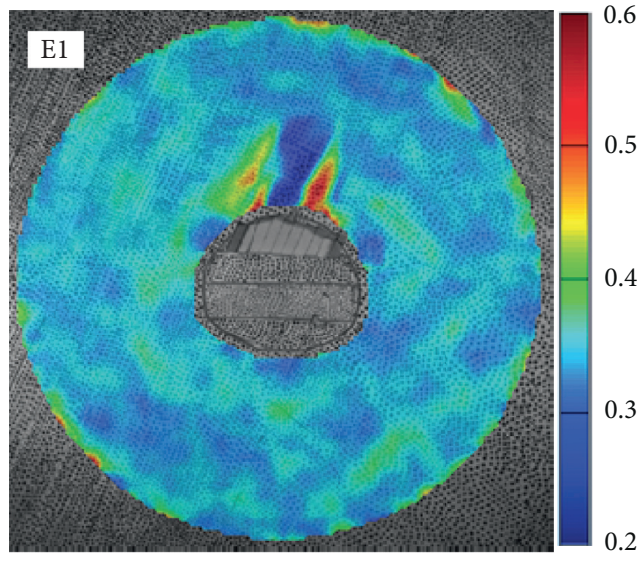

(a)

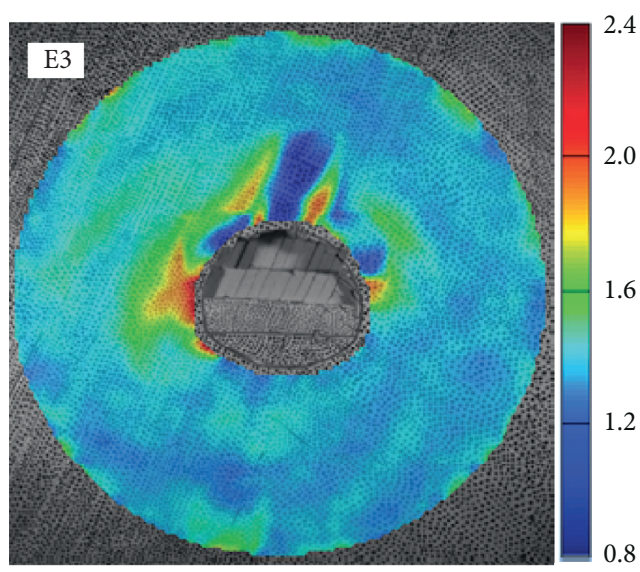

(c)

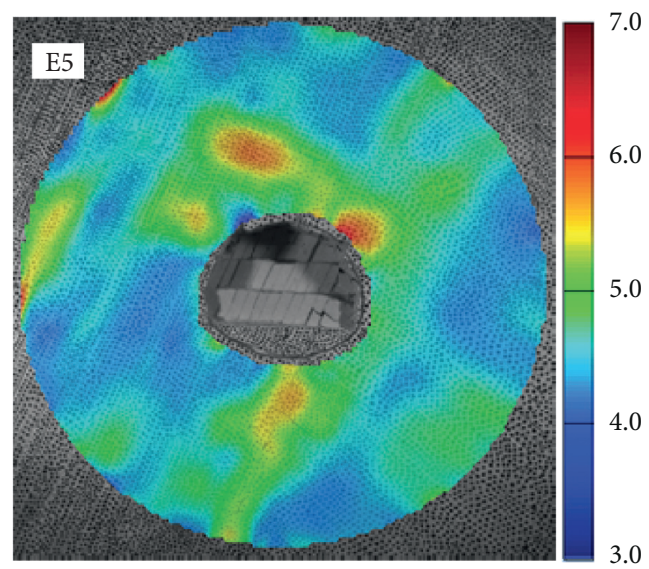

(e)

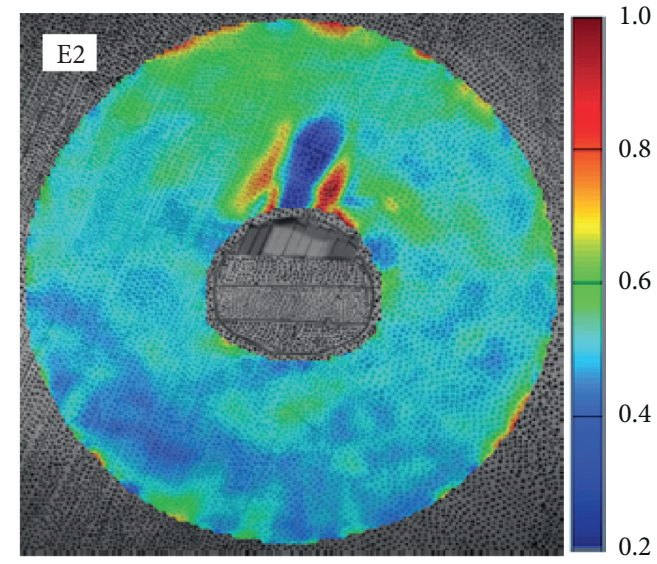

(b)

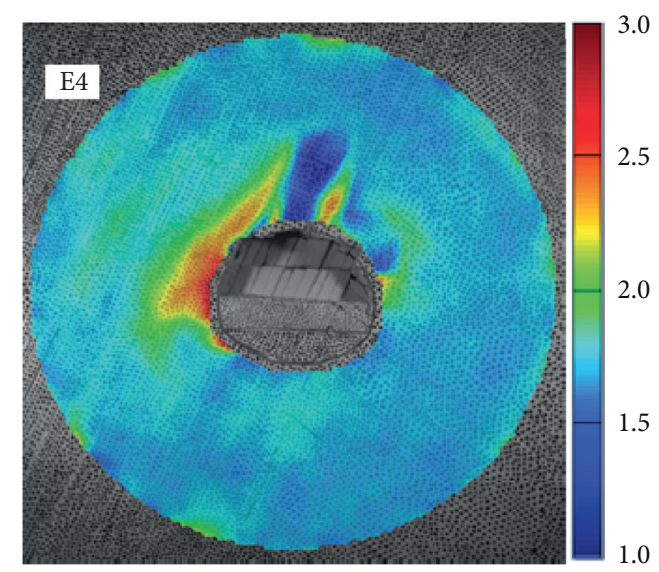

(d)

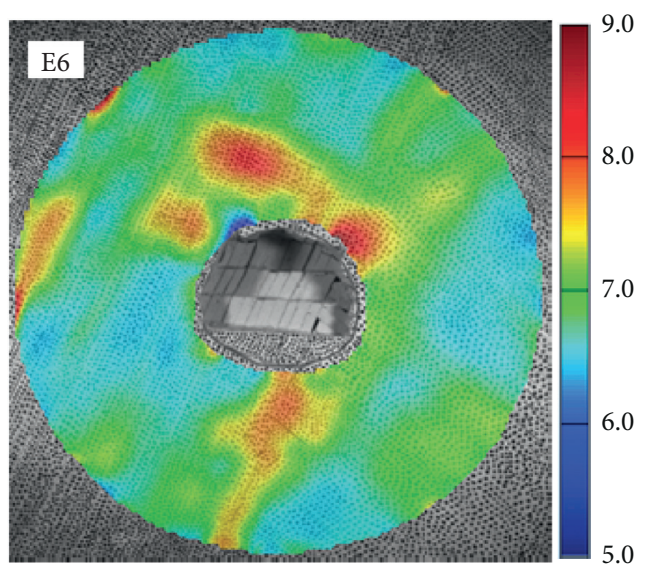

(f)

Figure 17: Continued. 


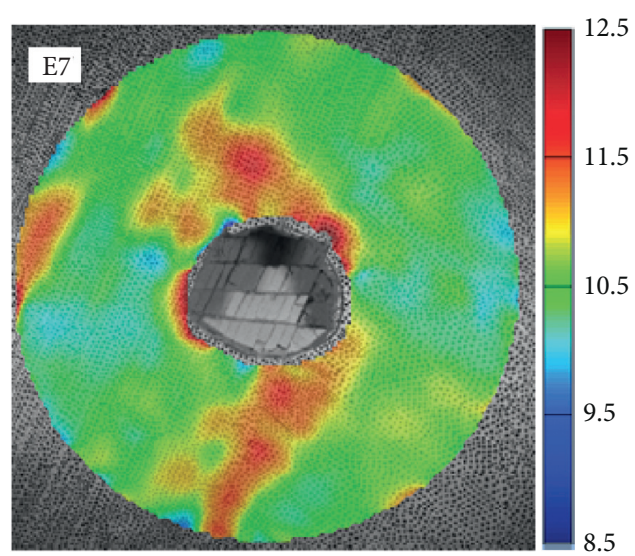

(g)

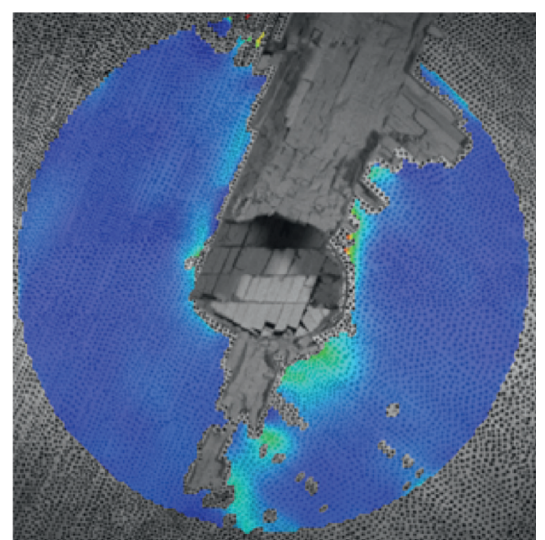

(h)

FIGURE 17: Evolution of displacement field around the tunnel by the DIC method (unit: mm).

$\varepsilon_{230}=\varepsilon_{x, l}\left(\cos ^{2} 230\right)+\varepsilon_{y, l}\left(\sin ^{2} 230\right)+\gamma_{x y, l}(\sin 230 \cdot \cos 230)$.

where $\varepsilon_{140}, \varepsilon_{185}$, and $\varepsilon_{230}$ are measured strains by red, yellow, and green strain gauges of right strain flower, respectively. Then substituting equations (17)-(19) into equations (13) and (14), two principal stresses $\sigma_{1, r}$ and $\sigma_{2, r}$ of the point can be acquired.

4.3.2. Distribution of the Maximum Principal Stress. The monitoring ring $\mathrm{A}$ around the tunnel was taken as an example. The spatial and temporal distribution diagram of calculated maximum principal stresses is shown in Figure 16(a), and the curves of stress concentrate factors are shown in Figure 16(b).

In excavation steps E1 and E2, the peak values of maximum principal stresses appeared at right and left shoulders and were $167.90 \mathrm{kPa}$ and $175.89 \mathrm{kPa}$, respectively. Stress concentration factor was defined as the ratio of measured maximum principal stress to initial maximum principal stress, $143 \mathrm{kPa}$. Therefore, the corresponding stress concentration factors were 1.17 and 1.23, since stress redistribution took place around the first bench due to rock mass in the area being removed. However, other positions were stable because they were far away from the excavation area. During steps E3 and E4, the range of stress redistribution extended to the second bench, and maximum principal stresses increased significantly. The maximum stresses occurred at the top of the tunnel in two steps, and stress concentration factors reached 1.51 and 1.70. It should be pointed out that the high stress acting on the third bench caused the fracture of weak contact surface between the third bench and its bottom rock mass. After steps E5 and E6 were completed, the range of stress redistribution extended to the full surrounding rocks above the ground. Both peak values of maximum stresses appeared at the vault of the tunnel and its concentration factors were 2.03 and 2.24, respectively. Moreover, in the same horizontal position, stresses near the fault were smaller than those on the other side. For example, the stress at point F3-A was less than that at F1-A, and the value at point S2-A was smaller than that at S1-A. The reason may be that there was more stress release in these positions due to more broken rock mass near the fault. During step E7, there were the maximum principal stresses at the vault, and the corresponding stress concentration factors reached 3.11. Finally, the high concentrated stress caused local rock blocks to fail, and a large area of the overlying strata collapsed and caved.

The following can be seen from the above analysis: (a) Stress distribution around the tunnel is very uneven in layered jointed rock mass, and it rises the uneven loads acting on the supporting system. (b) The effect of concentration stress is the important factor to cause the deformations and failure of surrounding rocks. The high concentrated stress made some key positions unstable and prone to failure. (c) The influence of the fault is that rock mass near the fault is weak and breakable due to mutual compression of unconformable rock layers on both sides, which makes support difficult. (d) The excavation of the third bench and the bottom arc area had great influences on the stress redistribution of surrounding rocks. Therefore, the delay distance between the bottom arc area and the third bench should not be too small, and the bottom arc should be excavated after the deformation of the tunnel above the ground becomes stable.

4.4. Displacement Field. The evolution process of displacement field on the model surface represented by the digital speckle nephogram is shown in Figure 17.

During the first excavation stage (E1 and E2), since rock mass in the first bench was removed, the largest displacement of surrounding rocks appeared at the left and right shoulders, and displacement values were $0.6 \mathrm{~mm}$ and $1.0 \mathrm{~mm}$, respectively. When the second stage (E3 and E4) was carried out, the displacement field of surrounding rocks changed obviously due to the second bench being excavated. The largest displacement was transferred to left sidewall of the tunnel and its values were $2.4 \mathrm{~mm}$ and $3.0 \mathrm{~mm}$, respectively. In process of the third stage (E5 and E6), the full- 
field displacements of surrounding rocks increased clearly, especially along the fault. The largest placement appeared at the right shoulder of the tunnel, followed by some places near the fault. The displacement values were $7.0 \mathrm{~mm}$ to $9.0 \mathrm{~mm}$. During the fourth excavation stage (E7), the displacements around the tunnel and along the fault increased continuously. The maximum displacements mainly occurred at left side and the vault of the tunnel, especially at the left side wall, left arc foot, and right shoulder. Their values were from $11.5 \mathrm{~mm}$ to $12.5 \mathrm{~mm}$, and the corresponding actual displacements were $460 \mathrm{~mm}$ to $500 \mathrm{~mm}$, which were relatively similar to the in situ deformations.

With the evolution of stress redistribution and surrounding rocks deformation, in area of severe displacements, some unstable positions failed firstly and they could be considered as key positions. After failure of key positions, large area caving occurred around the tunnel, which was consistent with the evolution process of surrounding rocks failure in practical engineering field.

\section{Discussion and Conclusions}

According to observation and analysis above, the failure of the Minxian tunnel is a progressive evolutionary process. The failure starts with cracking at several positions due to uneven concentrated stresses caused by effects of stress redistribution and excavation unloading. The damaged area enlarges gradually under high concentrated stresses. Finally, large scale of failure occurs around the tunnel. Those positions that failed firstly should be called key positions [39]. Reinforcement of key positions is an important basis for stability of the tunnel.

The deformation and failure mechanism of the Minxian tunnel could be investigated based on the experimental results and analysis. With the development of tunnelling process, the range of stress redistribution and stress concentration factors in surrounding rocks increased. Initial fractures and weak structural planes such as joints, beddings, and foliations extended and coalesced gradually under the concentrated stress, which led to increase of fragmentation degree of jointed rock mass. Especially near the fault, the rock mass was more likely to break and crush due to compressing and squeezing of angular unconformable rock layers on both sides of the fault.

The existing conventional tunnel supporting technologies have uniform supporting intensity and stiffness, while the jointed rock mass has nonuniform loads and deformation stiffness. During interaction process of supporting system and broken jointed surrounding rocks, failure always starts from key positions due to the uncoupling of mechanics characters such as strength, stiffness, or deformation between them. If reinforcing countermeasures are not carried out timely or there still are three uncoupling conditions in new technologies, a large-scale failure of surrounding rocks will occur.

In this paper, a physical model test was conducted to study the deformation process and failure mechanism of the tunnel excavated in stratified jointed rock mass. Based on the experimental results, the following conclusions could be obtained:

(1) During the whole tunnelling process, each excavation step had influence on the deformation of surrounding rocks. Among them, the influence caused by excavation of inverted arc area was greatest, followed by the third bench excavation. Therefore, during the construction, the inverted arc should be excavated after deformations of surrounding rocks above ground become stable.

(2) The main forms of surrounding rock deformation were surface cracking, sidewall spalling, bending of thin rock layer, and chip off-falling of the vault. With the development of excavation process, the displacement field of surrounding rocks changed frequently. Before large-scale collapse, the maximum displacement mainly appeared at left sidewall and right shoulder of the tunnel and the corresponding actual displacements were $460 \mathrm{~mm}$ to $500 \mathrm{~mm}$. Both areas were the most dangerous positions.

(3) The distribution of concentrated stresses in the surrounding rocks caused by effects of stratified structure and stress redistribution was very uneven when tunnelling in layered jointed rock mass, which would lead to the fact that the loads acting on the support system were also uneven. Since the stresses were released by the bending deformations of rock layers on both sides of the tunnel, the maximum concentrated stress appeared at the vault of the tunnel, and the concentration factor reached 3.11.

(4) The main influence of the fault on the surrounding rocks deformation was that surrounding rocks near the fault may be more broken due to the mutual compression of angular unconformity rock strata on both sides of the fault, and there may be more blocks prone to falling. However, the stress concentration coefficient in the fault area was relatively smaller than others.

(5) The deformation and failure of the Minxian tunnel represent a progressive development process. Firstly, the concentrated stresses in the surrounding rocks were nonuniform due to the layered jointed rock structure and stress redistribution, which caused surface cracking, bending of rock layers, and offfalling of rock lumps. Then, with the increase of exposed area of cross section, various deformation characteristics became more severe, which led to the 
increase of stress concentration degree and the deterioration of jointed and broken degree of surrounding rocks. Further, several key positions were prone to failure such as the locations of the maximum concentrated stress and the maximum displacement. Finally, the large area of failure on the surface, large-scale circumferential fractures, and massive collapse of overlying rock mass occurred suddenly.

\section{Data Availability}

The data used to support the findings of this study are available from the corresponding author upon request.

\section{Conflicts of Interest}

The authors declare that they have no conflicts of interest.

\section{Acknowledgments}

This work was supported by the Science and Technology Program of Transportation Department of Gansu Province.

\section{References}

[1] Q. Yin, H. W. Jing, G. W. Ma et al., "Investigating the roles of included angle and loading condition on the critical hydraulic gradient of real rock fracture networks," Rock Mechanics and Rock Engineering, vol. 51, no. 10, pp. 3167-3177, 2018.

[2] Z. Li, S. G. Liu, W. T. Ren, J. J Fang, Q. H. Zhu, and Z. L. Dun, "Multiscale laboratory study and numerical analysis of waterweakening effect on shale," Advances in Materials Science and Engineering, vol. 2020, Article ID 103725, 14 pages, 2020.

[3] Q. Meng, H. Wang, M. Cai, W. Xu, X. Zhuang, and T. Rabczuk, "Three-dimensional mesoscale computational modeling of soil-rock mixtures with concave particles," Engineering Geology, vol. 277, Article ID 105802, 2020.

[4] Z. G. Tao, C. Zhu, M. C. He, and M. Karakus, "A physical modeling-based study on the control mechanisms of Negative Poisson's ratio anchor cable on the stratified toppling deformation of anti-inclined slopes," International Journal of Rock Mechanics and Mining Sciences, vol. 138, Article ID 104632, 2021.

[5] Y. Wang, B. Zhang, S. H. Gao, and C. H. Li, "Investigation on the effect of freeze-thaw on fracture mode classification in marble subjected to multi-level cyclic loads," Theoretical and Applied Fracture Mechanics, vol. 111, Article ID 102847, 2021.

[6] F. Ren, C. Zhu, and M. He, "Moment tensor analysis of acoustic emissions for cracking mechanisms during schist strain burst," Rock Mechanics and Rock Engineering, vol. 53, no. 1, pp. 153-170, 2020.

[7] M. He, F. Ren, D. Liu, and S. D. Zhang, "Experimental study on strain burst characteristics of sandstone under true triaxial loading and double faces unloading in one direction," Rock Mechanics and Rock Engineering, 2020.

[8] M. C. He, F. Q. Ren, and D. Q. Liu, "Rockburst mechanism research and its control," International Journal of Mining Science and Technology, vol. 28, no. 5, pp. 116-124, 2018.

[9] G. L. Li and Y. Q. Zhu, "Control technology for large deformation of high stressed weak rock in Wushaoling tunnel," Journal of Railway Engineering Society, vol. 114, pp. 54-59, 2008.
[10] Y. Zhou, Study on mechanical characters of watery weakly consolidated sandstone during tunnel construction and its support countermeasure, Ph.D. thesis, Beijing Jiaotong University, Beijing, China, 2013.

[11] Z. Chen, C. He, G. Xu, G. Ma, and D. Wu, "A case study on the asymmetric deformation characteristics and mechanical behavior of deep-buried tunnel in phyllite," Rock Mechanics and Rock Engineering, vol. 52, no. 11, pp. 4527-4545, 2019.

[12] P. Lin, H. Liu, and W. Zhou, "Experimental study on failure behaviour of deep tunnels under high in-situ stresses," Tunnelling and Underground Space Technology, vol. 46, pp. 28-45, 2015.

[13] B. Chen, S. C. Zhang, Y. Y. Li, Z. K. Li, and H. J. Zhou, "Physical simulation study of crack propagation and instability information discrimination of rock-like materials with faults," Arabian Journal of Geosciences, vol. 13, no. 18, 2020.

[14] C. Zhu, M. C. He, M. Karakus, X. B. Cui, and Z. G. Tao, "Investigating toppling failure mechanism of anti-dip layered slope due to excavation by physical modelling," Rock Mechanics and Rock Engineering, vol. 53, pp. 3395-3416, 2020.

[15] Z. Tao, Y. Liu, L. Cheng, and Q. Yang, "Failure and stability analysis of Jinping-I arch dam based on geomechanical model test and nonlinear numerical analysis," Rock Mechanics and Rock Engineering, vol. 52, no. 7, pp. 2245-2260, 2019.

[16] Q. Y. Zhang, M. Y. Ren, K. Duan et al., "Geo-mechanical model test on the collaborative bearing effect of rock-support system for deep tunnel in complicated rock strata," Tunnelling and Underground Space Technology, vol. 91, Article ID 103001, 2019.

[17] Q. B. Zhang, L. He, and W. S. Zhu, "Displacement measurement techniques and numerical verification in 3D geomechanical model tests of an underground cavern group," Tunnelling and Underground Space Technology, vol. 56, pp. 54-64, 2016.

[18] S. C. Li, Q. Wang, H. T. Wang et al., "Model test study on surrounding rock deformation and failure mechanisms of deep roadways with thick top coal," Tunnelling and Underground Space Technology, vol. 47, pp. 52-63, 2015.

[19] Y. Xiang, H. Liu, W. Zhang, J. Chu, D. Zhou, and Y. Xiao, "Application of transparent soil model test and DEM simulation in study of tunnel failure mechanism," Tunnelling and Underground Space Technology, vol. 74, pp. 178-184, 2018.

[20] S. H. Park, T. Adachi, M. Kimura, K. Kishida, and M. Kikumoto, "Experimental study on tunneling in the ground with inclined layers and its simulation," in Modern Tunneling Science and Technology, T. Adachi, Ed., pp. 189194, Balkema, Rotterdam, Netherlands, 2001.

[21] S. Jeon, J. Kim, Y. Seo, and C. Hong, "Effect of a fault and weak plane on the stability of a tunnel in rock-a scaled model test and numerical analysis," International Journal of Rock Mechanics and Mining Sciences, vol. 41, no. 1, pp. 658-663, 2004.

[22] M. He, X. Jia, W. Gong, and L. Faramarzi, "Physical modeling of an underground roadway excavation in vertically stratified rock using infrared thermography," International Journal of Rock Mechanics and Mining Sciences, vol. 47, no. 7, pp. 1212-1221, 2010.

[23] M. C. He, W. L. Gong, H. M. Zhai, and H. P. Zhang, "Physical modeling of deep ground excavation in geologically horizontal strata based on infrared thermography," Tunnelling and Underground Space Technology, vol. 25, no. 4, pp. 366376, 2010.

[24] M. He, "Physical modeling of an underground roadway excavation in geologically $45^{\circ}$ inclined rock using infrared 
thermography," Engineering Geology, vol. 121, no. 3-4, pp. 165-176, 2011.

[25] M. Lei, L. Peng, and C. Shi, "Model test to investigate the failure mechanisms and lining stress characteristics of shallow buried tunnels under unsymmetrical loading," Tunnelling and Underground Space Technology, vol. 46, pp. 64-75, 2015.

[26] X. Sun, F. Chen, C. Miao et al., "Physical modeling of deformation failure mechanism of surrounding rocks for the deep-buried tunnel in soft rock strata during the excavation," Tunnelling and Underground Space Technology, vol. 74, pp. 247-261, 2018.

[27] Q. Y. Zhang, Y. Zhang, K. Duan, C. C. Liu, Y. S. Miao, and $\mathrm{D}$. $\mathrm{Wu}$, "Large-scale geo-mechanical model tests for the stability assessment of deep underground complex under true-triaxial stress," Tunnelling and Underground Space Technology, vol. 83, pp. 577-591, 2018.

[28] Y. R. Liu, F. H. Guan, Q. Yang, R. Q. Yang, and W. Y. Zhou, "Geomechanical model test for stability analysis of high arch dam based on small blocks masonry technique," International Journal of Rock Mechanics and Mining Sciences, vol. 61, pp. 231-243, 2013.

[29] S. C. Li, C. L. Gao, Z. Q. Zhou et al., "Analysis on the precursor information of water inrush in Karst tunnels: a true triaxial model test study," Rock Mechanics and Rock Engineering, vol. 52, no. 2, pp. 373-384, 2018.

[30] G. Y. Hou, Advanced Rock Mechanics, Science Press, Beijing, China, 2018.

[31] S.-C. Ko, D. L. Olgaard, and U. Briegel, "The transition from weakening to strengthening in dehydrating gypsum: evolution of excess pore pressures," Geophysical Research Letters, vol. 22, no. 9, pp. 1009-1012, 1995.

[32] W. M. Xiao, R. G. Deng, X. M. Fu, and C. Y. Wang, "Model experiments on deformation and strength anisotropy of columnar jointed rock masses under uniaxial compression," Chinese Journal of Rock Mechanics and Engineering, vol. 33, no. 5, pp. 957-963, 2014.

[33] L. Chang, H. Konietzky, and T. Frühwirt, "Strength anisotropy of rock with crossing joints: results of physical and numerical modeling with gypsum models," Rock Mechanics and Rock Engineering, vol. 52, no. 7, pp. 2293-2317, 2019.

[34] I. Yamaguchi, "Simplified Laser-speckle strain gauge," Optical Engineering, vol. 21, Article ID 213436, 1982.

[35] W. H. Peters and W. F. Ranson, "Digital imaging techniques in experimental stress analysis," Optical Engineering, vol. 21, no. 3, Article ID 213427, 1982.

[36] H. Munoz, A. Taheri, and E. K. Chanda, "Pre-peak and postpeak rock strain characteristics during uniaxial compression by 3D digital image correlation," Rock Mechanics and Rock Engineering, vol. 49, no. 7, pp. 2541-2554, 2016.

[37] X. P. Zhou, Y. T. Wang, J. Z. Zhang, and F. N. Liu, "Fracturing behavior study of three-flawed specimens by uniaxial compression and 3D digital image correlation: sensitivity to brittleness," Rock Mechanics and Rock Engineering, vol. 52, no. 3, pp. 691-718, 2018.

[38] M. Yukitaka, Theory of Elasticity and Stress Concentration, Wiley, New York, NY, USA, 2017.

[39] M. C. He, H. H. Jing, and X. M. Sun, Theory of Soft Rock Engineering Mechanics, Science Press, Beijing, China, 2002. 